\section{Tercio Creciente}

DOI: https://dx.doi.org/10.17561/rtc.20.6424 Investigación

Maneras de habitar los espacios desde la mirada estética

\section{Buscando la tierra de nadie. Obras contemporáneas de arte y matemáticas}

\author{
Looking for no man's land. Contemporary \\ works of art and mathematics
}

Sugerencias para citar este artículo:

Guida, Rosanna (2021). Buscando la tierra de nadie. Obras contemporáneas de arte y matemáticas. Tercio Creciente 20, (pp. 59-92), https://dx.doi.org/10.17561/rtc.20.6424

GUIDA, ROSANNA. Buscando la tierra de nadie. Obras contemporáneas de arte y matemáticas julio 2021, pp. 59-92, https://dx.doi.org/10.17561/ rtc.20.6424
Rosanna Guida rsnn.guida@gmail.com rosannaguida@fadbrera.edu.it https://orcid.org/0000-0002-9892-4345 Academia de Bellas Artes de Brera (Italia)
Recibido: 13/06/2021 Revisado: 20/07/2021

Aceptado: 20/07/2021 Publicado: 31/07/2021

\section{Resumen}

En este artículo, a la luz de lo que se desprende del análisis de Bruno Latour en el libro Investigación sobre los modos de existencia, investigo algunas relaciones entre las categorías literarias calvinianas de la ligereza, de la velocidad, de la exactitud, la visibilidad, la multiplicidad y la consistencia, transfiriéndolas a diferentes contextos artísticos y científicos y poniendo de relieve los flujos de intercambio en las fronteras entre los diferentes territorios del conocimiento artístico y matemático, en particular.

Comparadas, las obras de algunos artistas contemporáneos (Joseph Beuys, Michele Guido, Silvia Hell, Roni Horn, Armin Linke, Mark Lombardi, Sergio Lombardo, Sol Lewitt, Bruno Munari,

\section{Abstract}

In this article, based on Bruno Latour's analysis in the book Research on modes of existence, I investigate some relationships between the Calvinian literary categories of lightness, speed, accuracy, visibility, multiplicity and consistency, transferring them to different artistic and scientific contexts and highlighting the exchange flows at the borders between the different territories of artistic and mathematical knowledge, in particular.

Compared, the works of some contemporary artists (Joseph Beuys, Michele Guido, Silvia Hell, Roni Horn, Armin Linke, Mark Lombardi, Sergio Lombardo, Sol Lewitt, Bruno Munari, Jackson Pollock, Tomas Saraceno, Luigi Veronesi) and the works of the Contemporary mathematicians 


\section{Tercio Creciente}

DOI: https://dx.doi.org/10.17561/rtc.20.6424

Investigación
Maneras de habitar los espacios desde la mirada estética Julio 2021
Jackson Pollock, Tomas Saraceno, Luigi Veronesi) y las obras de los matemáticos contemporáneos Alexander Groetendieck y Fernando Zalamea, revelan la reciprocidad epistemológica en función de la ampliación de la percepción humana.

Utilizando los métodos de la filosofía pragmática, a través del uso de la hoja-mundo y de los gráficos existenciales de Charles Peirce, la lógica de las analogías, de las similitudes y de los contrastes dialécticos y la lógica intuicionista, surgen, en las obras estudiadas, las relaciones fenomenológicas entre los elementos expresivos de las obras de los artistas investigados y los significados actuales, vinculados a los diferentes ámbitos disciplinarios. Por último, con las herramientas ofrecidas por la A/R/ Tografía, se traza un mapa de relaciones entre los elementos icónicos, las categorías calvinianas y los conceptos matemáticos de homotetia, isomorfismo, lista, red, superficie, proceso estocástico.

\section{Palabras clave}

Arte, categorías, epistemológico, matemáticas, percepción
Alexander Groetendieck and Fernando Zalamea reveal epistemological reciprocity based on the expansion of human perception.

Using the methods of pragmatic philosophy, through the use of the world-leaf and the existential graphics of Charles Peirce, the logic of analogies, similarities and dialectical contrasts and intuitionist logic, emerge, in the works studied, the phenomenological relationships between the expressive elements of the works of the investigated artists and the current meanings, linked to the different disciplinary fields. Finally, with the tools offered by the A / R / Tography, a map of relationships between the iconic elements, the Calvinian categories and the mathematical concepts of homothety, isomorphism, list, network, surface, stochastic process is drawn.

\section{Keywords}

Art, categories, epistemological, mathematics, perception 


\section{Tercio Creciente}

DOI: https://dx.doi.org/10.17561/rtc.20.6424 Investigación
Maneras de habitar los espacios desde la mirada estética Julio 2021

\section{Contextos, redes, atlas, mapas, a/r/t/ografias}

En el marco de los temas relativos a las relaciones entre arte y ciencia, el texto de Bruno Latour, titulado Encuesta sobre los modos de existencia, publicado en 2012, juega un papel importante porque problematiza el sentido de las 'categorías' como instrumentos de comprensión de la realidad.

Como afirma Cristina Baldacci en la introducción a su texto Archivos imposibles (2016, p. 9), “...archivamos rápidamente todo en forma de lista, catálogo o inventario, con la esperanza de que dar algún orden a conceptos, imágenes y datos, nos impida perderlos. Y parece que, en este momento, la forma más eficaz de representar la realidad es pasar por la apropiación y el montaje de sus fragmentos, en una especie de ars combinatoria, que selecciona y ensambla objetos que se encuentran en su mayoría, o específicamente buscados".

Emocionalmente, se advierte una especie de embriaguez cuando se redacta una lista o se deconstruyen atlas, inventarios y clasificaciones, que no son sino redes de flujos de información y de conexiones entre conocimientos.

De por sí la lista es un principio matemático abstracto porque como afirma Umberto Eco en su texto Vértigo de la lista (2009, p.39), "Ia lista (potencialmente infinita porque incluye la presencia de un etcétera) es también un intento poético y utópico de agarrar lo que no se conoce o sigue siendo incomprensible (...) Es algo que suscita un placer inquieto, que nos hace sentir la grandeza de nuestra subjetividad, capaz de querer algo que no podemos tener."

Por su parte, el dibujo es una herramienta de comprensión.

Como afirma Asución Jodàr Minarro en su texto Por dibujado y por escrito (2006, p. 7), "hay varios puntos de vista desde los cuales mirar la complejidad del Dibujo, también en relación con la enseñanza y la investigación."

Lo que abre la posibilidad de utilizar el diseño como instrumento de ayuda a la comprensión de una red de relaciones complejas, con la perspectiva de desarrollar nuevas conexiones significativas.

Puede ser que en el desarrollo de las conexiones se llegue a un punto ciego, pero como afirma Rita Irwin (2017, pp.134-167), “(...) la investigación es vital cuando se relacionan entre sí cosas que parecían no tener ninguna conexión entre sí, sabiendo que siempre es posible explorar nuevas conexiones. (...) El propio proceso de investigación es importante. Y los a/r/ tográficos prefieren pensar que las prácticas de los artistas y de los educadores son ocasiones para la creación de conocimiento."

Tanto los artistas como los científicos tratan de definir y distinguir su campo de acción, como si se sintiera un cierto temor de 'invadir'. La idea de permanecer confinados en un campo definido podría ser reconfortante y de ayuda. Nos movemos como si estuviéramos en un mapa, 
delimitando los territorios a través de fronteras y quizás usando colores vivos para definir los límites. Cuando estamos en el territorio 'ciencia' estamos seguros de que no estamos en el territorio 'arte'; cuando estamos en el territorio 'política' no estamos ni en el territorio 'ciencia' ni en el territorio 'arte', pero pronto nos damos cuenta de que el campo de la ciencia está invadido por elementos que parecen más bien formar parte de elementos que provienen del arte, y viceversa. Por lo tanto, la especificación de los diferentes campos no ayuda en esta búsqueda. Entonces, puede ser una buena manera de pensar en las fronteras entre los territorios, no como elementos de separación sino como lugares de intercambio y tráfico de conexiones. Y, en esto, nos ayuda la noción de actor-red introducida por Bruno Latour (2008): si en vez de tratar de los campos, hablamos de redes, la perspectiva del razonamiento cambia y se redistribuye en los diversos campos de maneras diferentes. La red no es un dispositivo técnico (por ejemplo, el ferrocarril), sino un flujo que permite el desplazamiento.

Por ejemplo, dice Latour (2012, p. 44): “...¿ialguna vez pensaste en una conexión entre Ucrania y el risotto?... quizás no. La conexión se descubre en cambio, pensando en las redes en términos de flujo que permite el desplazamiento.... porque es el gas que viene de Ucrania que permite cocinar el risotto."

El concepto de red oculta las ideas de movimiento y sorpresa.

A través del concepto de red exploramos las entidades necesarias para la existencia de una respecto a la otra. Pero lo que se gana en la libertad de movimiento se pierde en la especificidad del campo-sujeto.

Entonces nos enfrentamos a un problema: o bien reconocemos la existencia de una especificidad y de las diferencias entre los campos de acción-conocimiento, o bien todo es un flujo. ¿Cómo mantenemos unida la heterogeneidad de las asociaciones con lo específico que caracteriza a un campo?

Hay una noción de límite que no depende ni de la noción de campo ni de la noción de red. Por lo tanto, en lugar de hablar de fronteras infranqueables, se tratará de conceptualizar un tipo de redes para que la situación se defina a través de una lista (de vez en cuando específica), de las entidades de las que se dirá que están asociadas, movilizadas y reclutadas, traducidas para participar en una determinada situación.

Si queremos construir una red, el sentido de una situación, como dice Latour, se define gracias a dos tipos de datos: el de las asociaciones sorprendentes e ilimitadas y el limitado, hecho de entidades específicas.

Y, sobre las redes y los mapas en el arte, cito el texto de Lorenza Pignatti, Mind the map [Cuidado con el mapa] (2011), que explora, a través de algunas contribuciones de estudiosos de diversa procedencia, la forma en que los mapas y los gráficos han sido utilizados por los artistas en forma epistemológica y se han convertido ellos mismos en expresión artística. Lorenza Pignatti $(2011$, p. 7) observa: "Mapas y atlas son archivos de datos georeferenciales y herramientas para investigar relaciones espaciales." 
Por ejemplo, los diagramas de las estructuras narrativas, realizados por el artista Mark Lombardi, constituyen cartografías tácticas, verdaderos sociogramas, porque estudian las conexiones entre criminales internacionales, traficantes de armas, oficiales corruptos y agentes secretos, y visualizan la constelación reticular de los vínculos políticos presentes en diferentes partes del mundo. Estos sociogramas resultan muy útiles para la investigación de la realidad; de hecho, dice Jameson (1995), si se utilizan las categorías perceptivas consolidadas, difícilmente es posible comprender los sistemas del mundo contemporáneo.

Esto también define la estética de los mapas cognitivos.

Definir los contextos es, de por sí, una empresa notable, porque la identificación y la elección de las variables que entran en juego y el peso de cada variable en la construcción de un contexto es, de por sí, un trabajo de equilibrios y, por tanto, criticable. Sin embargo, es un trabajo que se hace necesario para poder atribuir valores, significados y perspectivas a las investigaciones. En los ejemplos analizados aquí, los contextos son muy diferentes entre sí y resulta interesante hacer un ejercicio de red y de conexiones, poniendo en relación entre sí las similitudes y los contrastes.

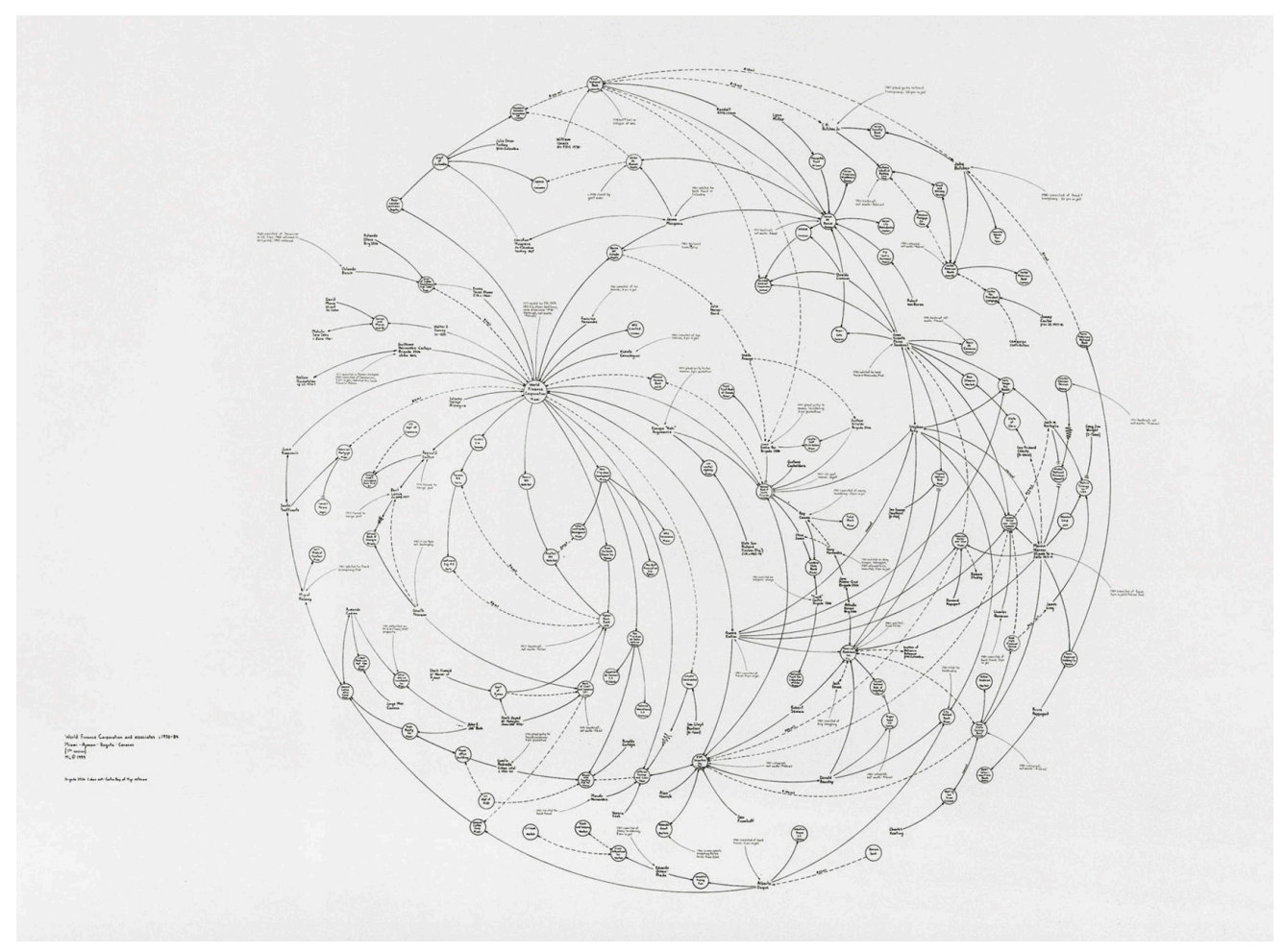

Mark Lombardi, World Finance Corporation and Associations [Corporación Financiera Mundial y Asociaciones] $(1970$ - 1984), 7 th versiòn, $175,577 \times 213,36 \mathrm{~cm}$ 


\section{Tercio Creciente}

Maneras de habitar los espacios desde la mirada estética

DOI: https://dx.doi.org/10.17561/rtc.20.6424

\section{Enfoques pragmáticos, constructivos y fenomenológicos.}

Los contextos se crean con la experiencia o se definen mediante axiomas y modelos, según unas reglas a las que luego hay que atenerse.

En un contexto constructivo, por ejemplo, el mundo en el que vivimos es el resultado de la actividad constructora de nuestras estructuras cognitivas $y$, por lo tanto, se sitúa en una perspectiva subjetiva y relativa. El constructivismo es un movimiento cultural y artístico que nace en Rusia, inmediatamente después de la revolución de 1917, con la idea de rechazar el modelo del arte por el arte, a favor del arte como práctica dirigida hacia fines sociales.

Pero el adjetivo 'constructivo' se aplicó a cualquier objeto construido o esculpido, a cualquier proyecto tanto tridimensional como bidimensional, que tuviera reminiscencias euclidianas y que fuera una elaboración de líneas rectas o de líneas curvas trazadas con el compás. (Rickey, 1995).

De ahí, la confusión con la abstracción.

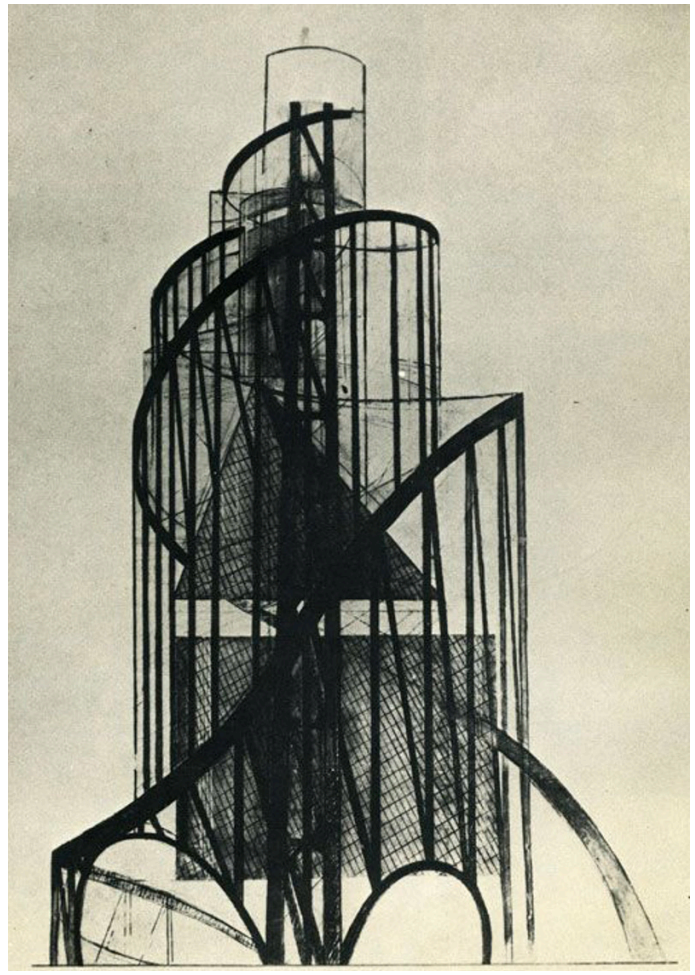

Vladimir Tatlin (1919). Monumento a la tercera internacional. 


\section{Tercio Creciente}

DOI: https://dx.doi.org/10.17561/rtc.20.6424 Investigación
Maneras de habitar los espacios desde la mirada estética

Julio 2021

En psicología, el constructivismo es un enfoque que surge de una concepción del conocimiento como construcción de la experiencia personal, más que como reflejo o representación de una realidad independiente. ¿Pero qué es la experiencia?

El concepto de experiencia ha experimentado con el tiempo desarrollos diferentes. Aquí consideramos el acercamiento a la experiencia propuesta en la filosofía pragmática, cuyo origen se remonta a Charles Peirce (2009), que fue matemático, lógico, científico, filósofo y semiólogo.

Para los pragmáticos, la verdad se identifica con las experiencias concretas y las operaciones conexas. En esta óptica se enmarca también la filosofía de John Dewey (1934), pedagogo además que filósofo, según el cual el pensamiento es un proceso activo que depende de un comportamiento y de una creencia.

Dewey llamó instrumentalismo a su pensamiento filosófico. El instrumentalismo se basa en una concepción de la experiencia como relación entre el hombre y el medio ambiente, donde el hombre no es un espectador pasivo, sino que interactúa con lo que le rodea. El pensamiento del individuo nace de la experiencia, esta última en el sentido de la experiencia social. La educación, la formación deben abrir el camino a nuevas experiencias y a la potenciación de todas las oportunidades para un desarrollo ulterior.

El individuo está en contacto constante con su entorno, reacciona y actúa sobre él. Portanto, la experiencia educativa debe partir de la cotidianidad en la que el sujeto vive. Posteriormente, lo que se ha experimentado debe adoptar progresivamente una forma más plena y organizada. La experiencia es realmente educativa en el momento en que produce la expansión y el enriquecimiento del individuo, conduciéndolo hacia el perfeccionamiento de sí mismo y del ambiente. Un entorno en el que se aceptan las pluralidades de opiniones de diferentes grupos en contraste, favorece el desarrollo progresivo de las características del individuo.

Escribe Merleau-Ponty (2003, p. 549): “El mundo es inseparable del sujeto, pero de un sujeto que no es más que una proyección del mundo; el sujeto es inseparable del mundo, pero de un mundo que el sujeto mismo proyecta."

Se advierte una necesidad de integración entre la sensibilidad, movida instintivamente por reglas que se han codificado y estratificado en la experiencia, hasta convertirse en automáticas e innatas y la posibilidad de descubrir nuevas relaciones entre las cosas con la ayuda de modelos que introducen otros elementos desconocidos o que no se prestan a ser considerados sólo desde el punto de vista de la sensibilidad. Por ejemplo, las acuarelas de Klee (2009) son un testimonio de su búsqueda de vibraciones a través de métodos cuantitativos y no sólo basados en la experiencia de relaciones armónicas subjetivas. 


\section{Tercio Creciente}

Revista de Estudios en Sociedad, Artes y

Gestión Cultural

ISSN: 2340-9096

DOI: https://dx.doi.org/10.17561/rtc.20.6424

Investigación

Maneras de habitar los espacios desde la mirada estética

Julio 2021

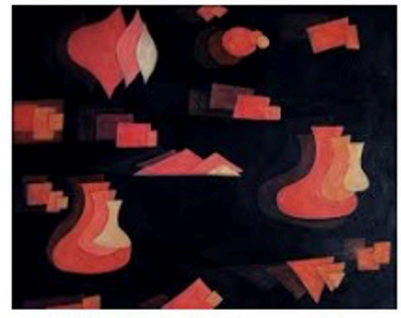

$\mathrm{R}$ come rosso - isabelladami isabelladami.wordpress.com

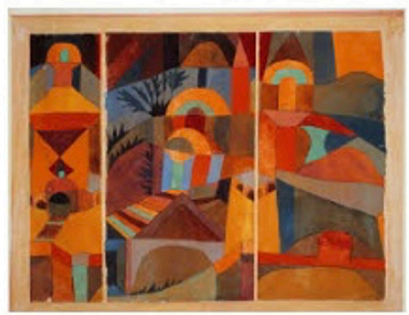

Temple Gardens - Klee (met afbeelding... pinterest.it

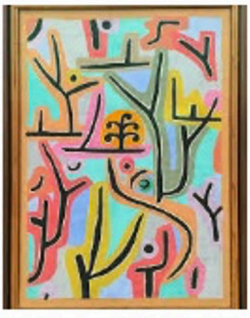

Paul Klee astratto alla ... travelglobe.it

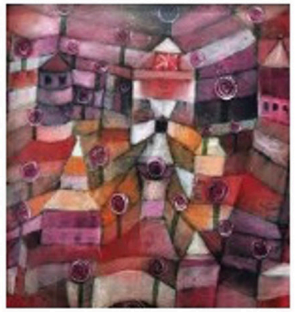

Paul Klee, biografia, stile, o... lacapannadelsilenzio.it

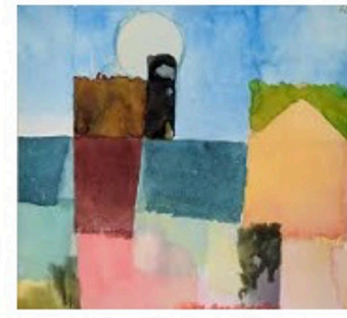

salida de la luna st . Germain, 19... it.artsdot.com

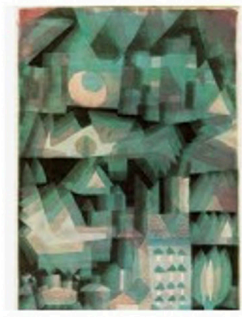

Paul Klee - Città di sog... criticamente.com

Paul Klee (1914) acuarelas
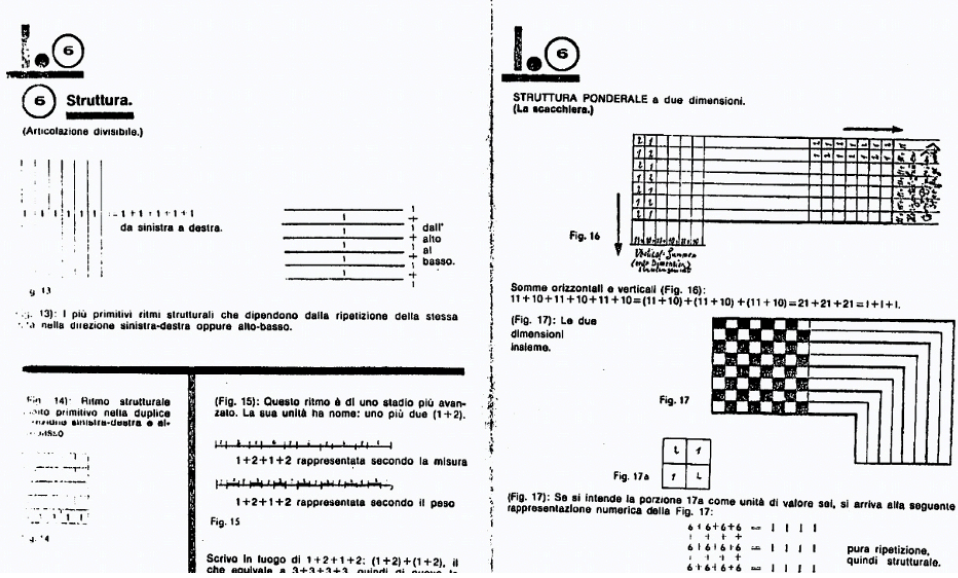

Paul Klee (1914) Teoría de la forma y de la figuración, apuntes 


\section{Tercio Creciente}

DOI: https://dx.doi.org/10.17561/rtc.20.6424 Investigación
Maneras de habitar los espacios desde la mirada estética Julio 2021

Lo que es importante tener en cuenta es que no hay significado sin contexto.

Pero el contexto se puede crear por sí mismo. Por ejemplo, I. Calvino (1993) propone, en sus Lecciones americanas, la categoría de la 'visibilidad', con la cual se puede razonar por imágenes y construir una lógica espontánea de las imágenes.

Y nos anima a proponer también ejercicios de imaginación para definir los contextos o a construir las estructuras de un cuento o de una obra.

La visión proporciona conocimiento, como atestigua el atlas de Aby Warburg, Mnemosyne (2002), construido enteramente para asociaciones de imágenes o, también, la obra de Karl Blossfeldt, El encanto de la flora, de 1930. Por ejemplo, la serie de 'equisetums' sugiere formas para diseñar arquitecturas. Las secciones geométricas de las plantas se vuelven objeto de reflexiones sobre las simetrías, los ritmos, las relaciones armónicas y, por tanto, objeto de estudio matemático
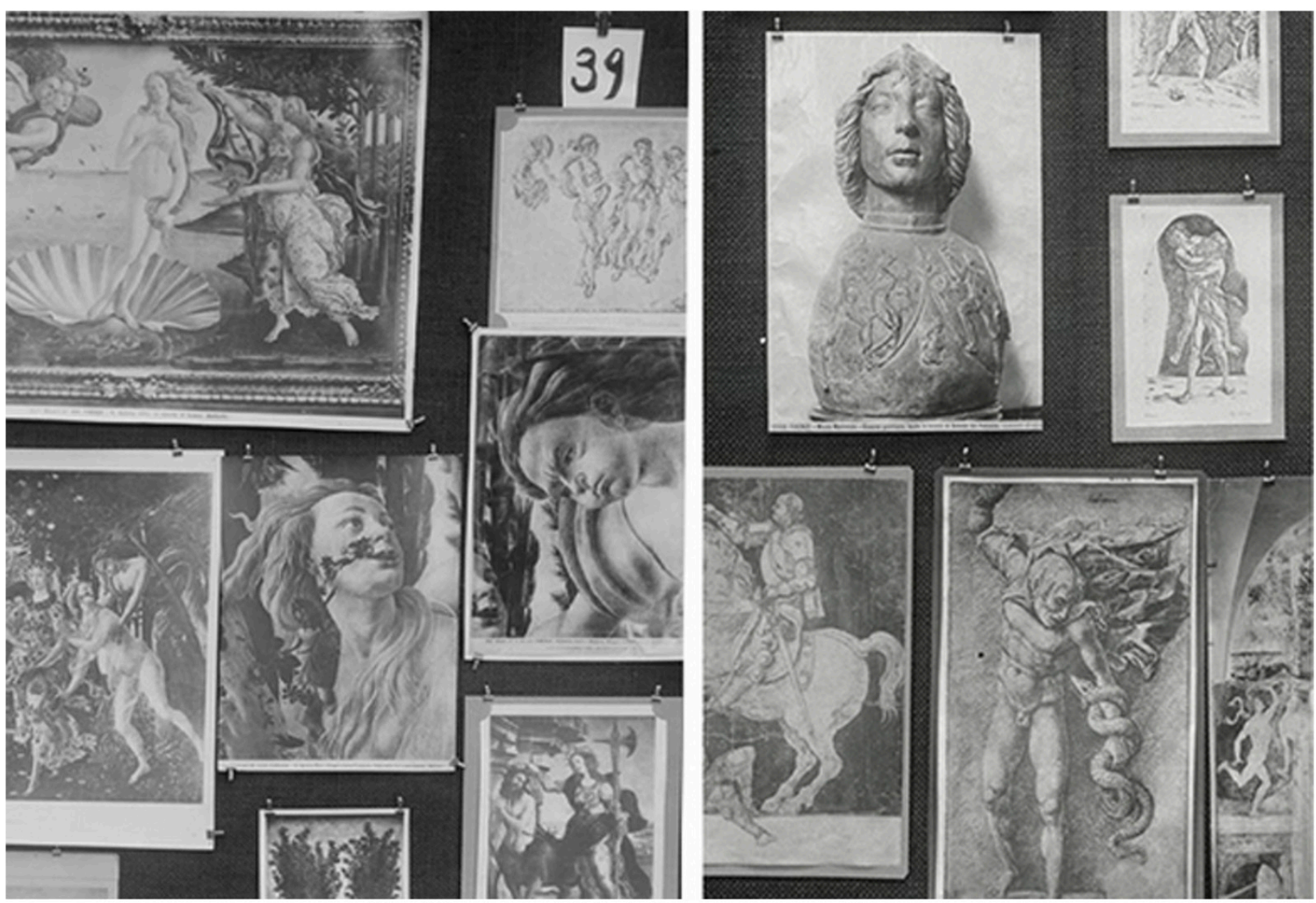

Aby Warburg (1927) Mnmosyne, villa romana 


\section{Tercio Creciente}

DOI: https://dx.doi.org/10.17561/rtc.20.6424
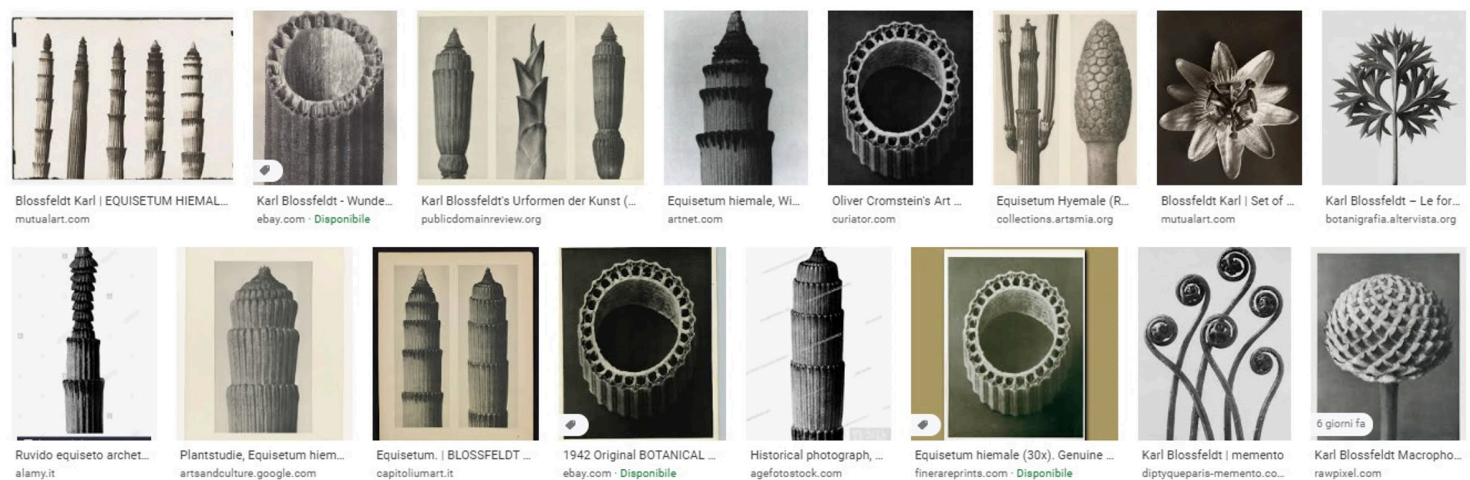

1942 Original BOTANI
ebay.com Disponibile

Oliver Cromstein's Art

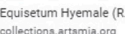

Maneras de habitar los espacios desde la mirada estética

Karl Blossfeldt (1930) El encanto de la flora, Equisetum

Varela define la 'neuro-fenomenológica' su enfoque conexionista, con el que intenta conectar la ciencia cognitiva moderna con la experiencia humana, situando su investigación en la línea de la tradición filosófica europea de la fenomenología. Mirando a través de la óptica 'neuro-fenomenológica' conexionista “Muchos de los objetivos del conocimiento (como la visión y la memoria) parecen ser tratados mejor por sistemas compuestos por muchos componentes simples, los cuales, una vez conectados según las normas adecuadas, dan lugar al comportamiento global correspondiente al objetivo deseado" (Varela, Thompson y Rosch (1991, p. 113).

Las matemáticas, la lógica, las categorías y el arte.

Fernando Zalamea (2019), matemático y filósofo contemporáneo, une el pragmatismo de Peirce con las teorías del matemático Groetendieck y desarrolla una serie de gráficos existenciales -que son un tipo de notación visual o diagramática para las expresiones lógicas, propuesto por Peirce, para crear interconexiones entre todos los mundos del conocimiento, incluido el mundo del arte. 


\section{Tercio Creciente}

OI: https://dx.doi.org/10.17561/rtc.20.6424

Investigación

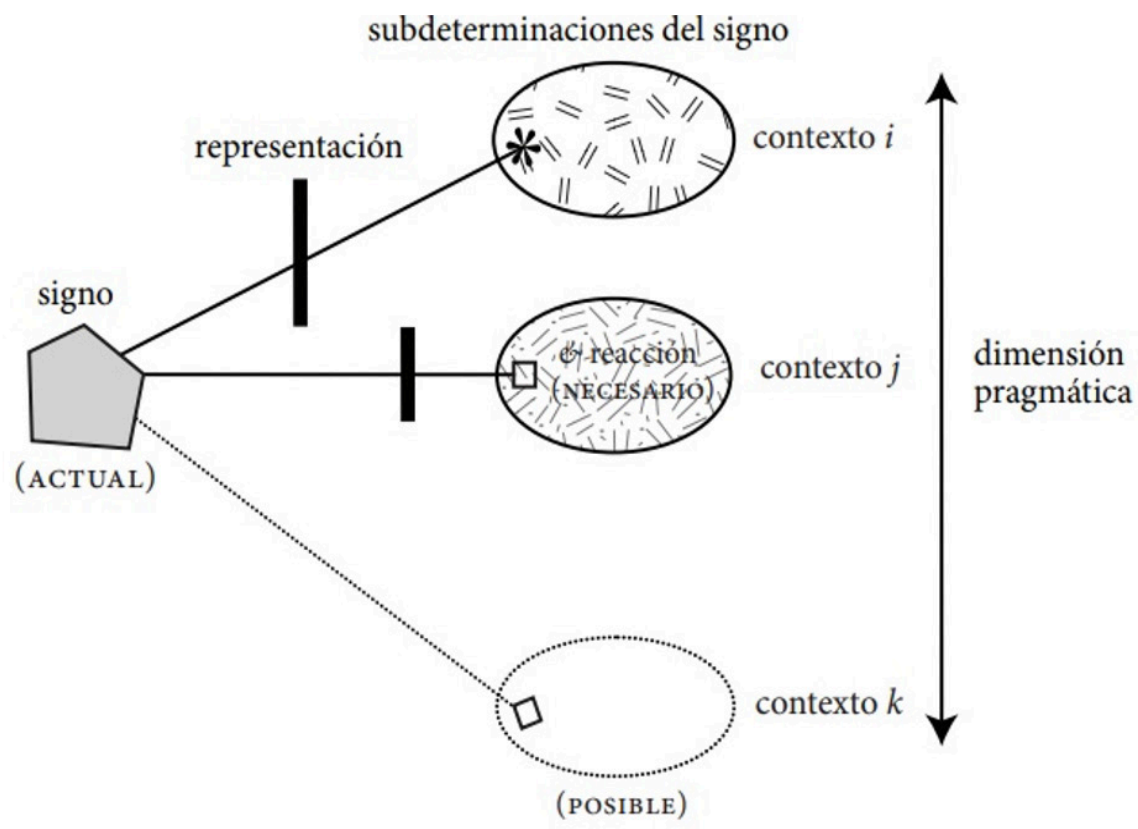

Fernando Zalamea (2019) Esquema de la dimensión pragmática de Peirce

En su guía de la obra matemática y filosófica de Groetendieck, Zalamea (2016, 2017 y 2019) dedica un capítulo entero a la descripción de los entresijos culturales entre las matemáticas, el arte, la literatura, la música y el cine. Para explorar estos entrelazamientos utiliza algunas categorías lógicas, palabras y conceptos, que expresan tanto aspectos matemáticos como científicos. Por ejemplo, en el análisis del Guernica de Picasso utiliza las categorías de arriba y abajo (en relación también con el tamaño de la pintura), de la iteración y del movimiento, a través de las triangulaciones, las inversiones, los cortes, para ponerlas en relación con La clef des songes de Groetendieck, donde este elabora una geometría del movimiento y del desplazamiento o donde las triangulaciones de las categorías lo ayudan a formar una geometría de la iteración. 


\section{Tercio Creciente}

Maneras de habitar los espacios desde la mirada estética

Julio 2021

DOI: https://dx.doi.org/10.17561/rtc.20.6424 Investigación

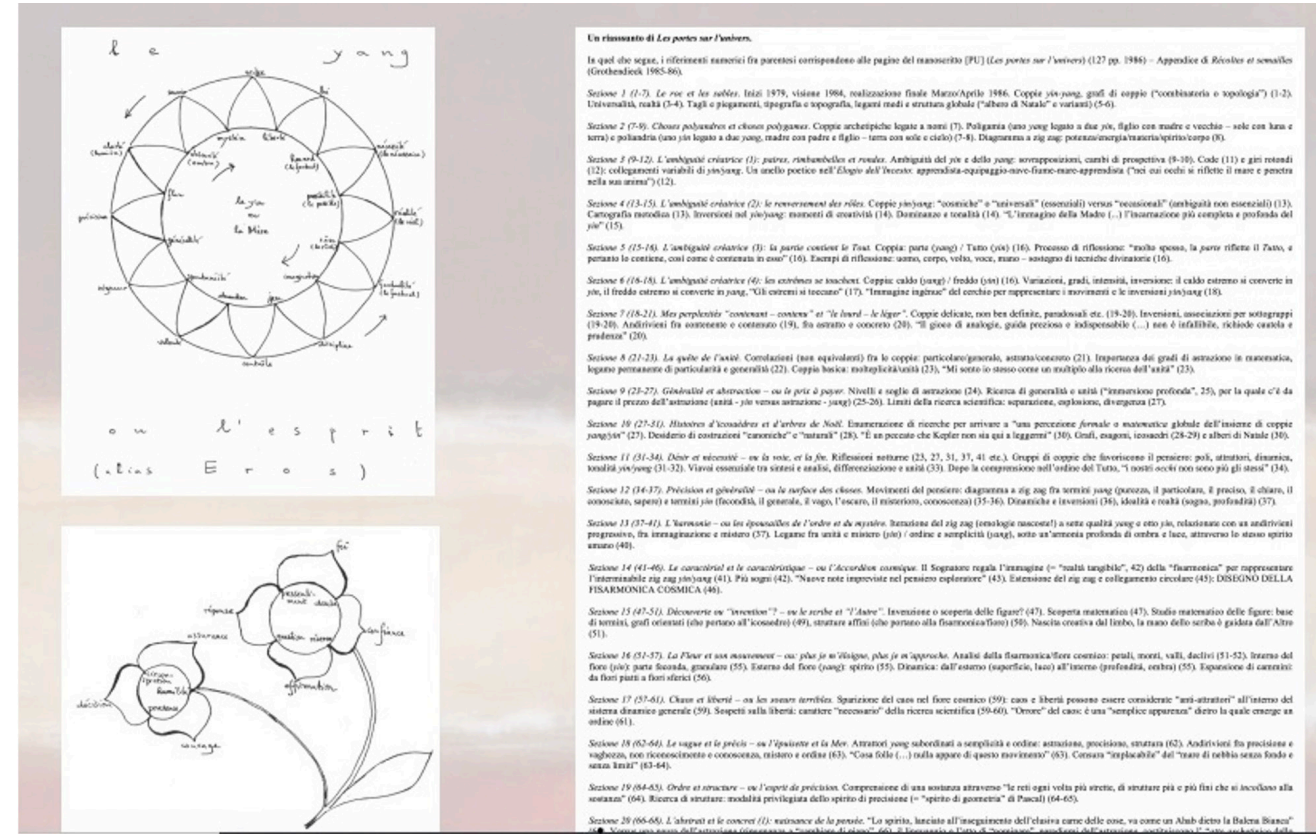

Alexander Grothendieck y Fernando Zalamea (2017) Las puertas del universo (una síntesis).

El caso de las categorías desencadena un discurso sobre una doble vía, es decir, por una parte, la identificación de las categorías mismas y la atribución de los criterios y de las características que definen las distintas categorías y, por otra, la cartografía de las categorías, para orientarse en la atribución de los significados y en la elección de los itinerarios lógicos, para los diferentes contextos y para las diferentes 'figuras' que se pueden formar componiendo entre sí los contextos y los recorridos.

Durante el último seminario celebrado por Fernando Zalamea en la sede de la asociación Mechrì, en Milàn, titulado Técnicas de las matemáticas contemporáneas para el desarrollo actual de la filosofía, en un diálogo directo, Zalamea ponía el acento en el hecho de que las lógicas con las que se pueden construir mundos posibles, gráficos y mapas, pueden ser diferentes, clásicas y no clásicas. Y que, al principio se puede decir todo y de cualquier manera; luego, cuando se definen los axiomas y los modelos, hay que estar dentro de las reglas..

Zalamea propone, por ejemplo, una posible invención para capturar la disipación entre lenguaje e imagen, como sucede en el atlas de Warburg e intenta construir una hoja-mundo con los escritos del matemático Galois (1811-1832), acercándolos y ensamblando en un único contexto. 


\section{Tercio Creciente}

Investigación

Maneras de habitar los espacios desde la mirada estética

Julio 2021

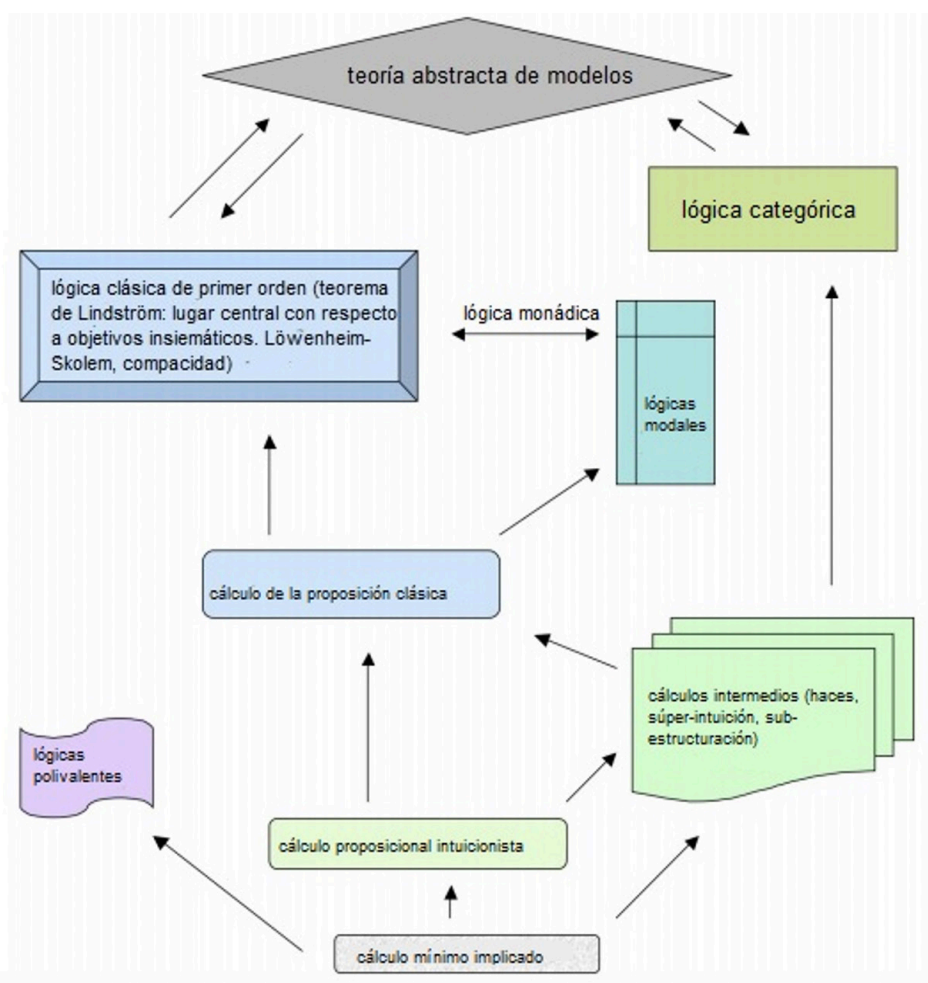

Fernando Zalamea (2017) Un esquema-síntesis de las lógicas contemporáneas

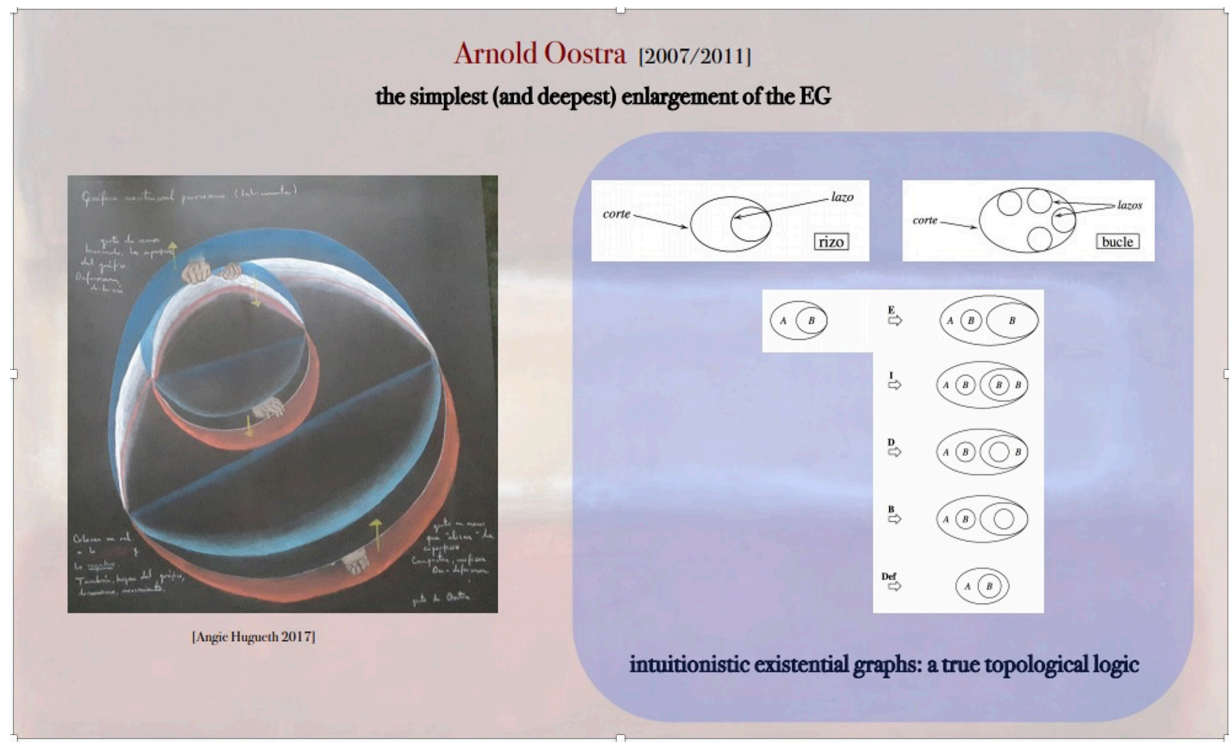

Fernando Zalamea (2017) Un ejemplo de expansión de los gráficos existenciales a través de la lógica intuicionista 


\section{Tercio Creciente}

Revista de Estudios en Sociedad, Artes y

Gestión Cultural

ISSN: 2340-9096
Maneras de habitar los espacios desde la mirada estética

DOI: https://dx.doi.org/10.17561/rtc.20.6424

Investigación

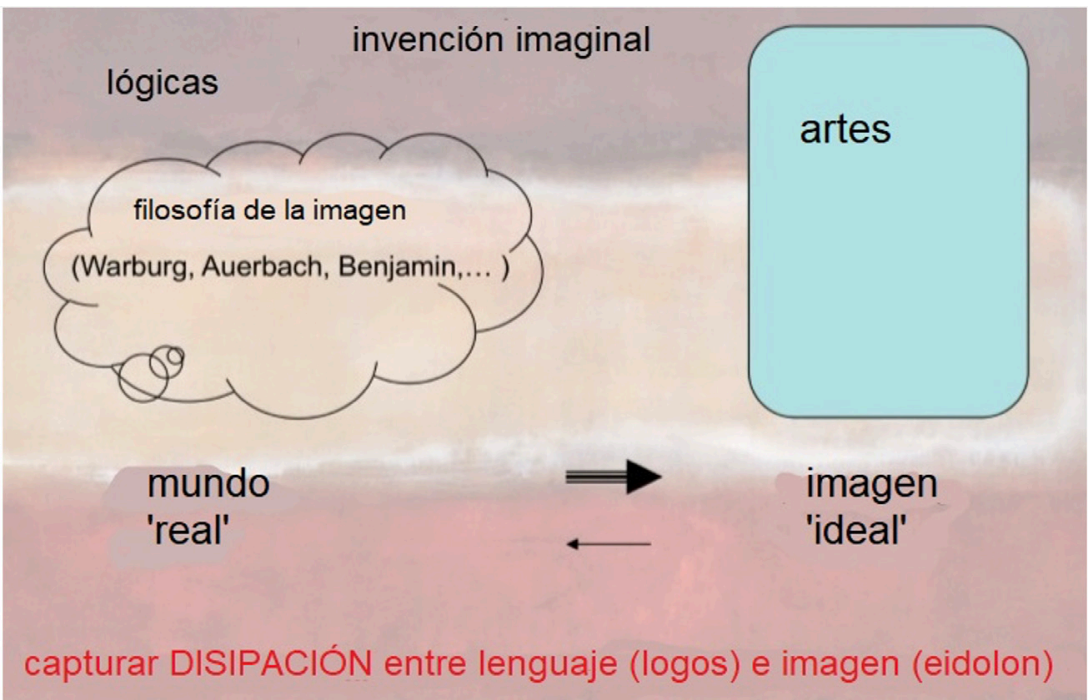

Fernando Zalamea (2017) Lenguaje e imágen (acción) y Aby Warburg

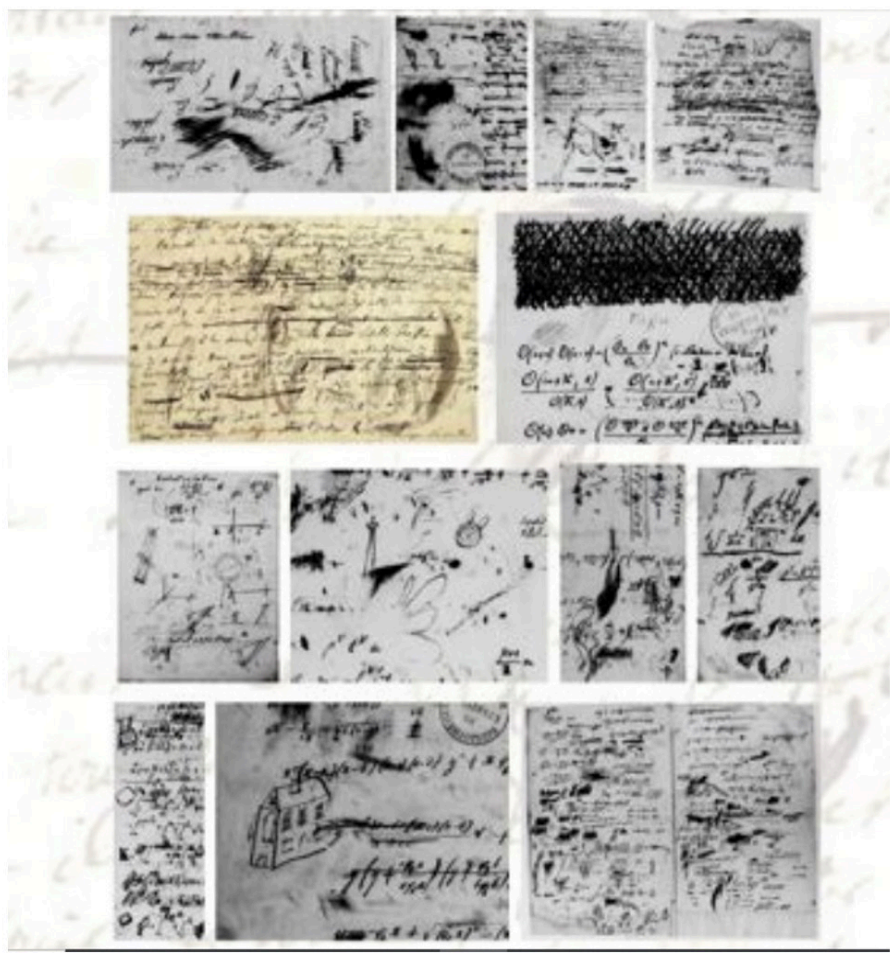

Fernando Zalamea (2017) 'Hoja-mundo' compuesto con los escritos de Galois 
La hoja-mundo es una expresión de Charles Sanders Peirce, que está en la base de la lógica del filósofo y significa el hecho de que incluso la más simple de las inferencias implica dentro de sí una filosofía del universo y por lo tanto incluso el más simple grafismo, signo, huella, implica dentro de sí una filosofía del universo.

Carlo Sini, filósofo y gran estudioso de Peirce, reflexiona sobre los gráficos existenciales y pone de relieve la importancia de los mapas para orientarse en la geografía de las hojas-mundo.

Según Sini (2007, pp.175):

"todo mapa presupone (y puesto que lo presupone no puede representarlo, es lo que le queda fuera) un interés ligado a un fin: es este fin que sugiere lo que un mapa debe o no debe representar. Si quiero mapear cuántos abetos hay en un bosque, me imagino un cierto tipo de mapa; si el objetivo es encontrar la salida del bosque hacia el este, el mapa será totalmente diferente. Esto significa que los presupuestos de cada mapa deben ser tenidos en cuenta por quien la construye y luego por quien la usa, para no caer en la ingenuidad de creer que la virtud del mapa consiste en decir la verdad supuesta objetiva y en símisma del territorio. El hecho es que no existe tal verdad: es sólo el fruto de nuestra imaginación supersticiosa que cree que las cosas, tal como las conocemos, son también independientes del conocimiento que tenemos: que son el presupuesto de todo conocimiento (de hecho no podemos inventarnos a gusto) es un hecho, pero que no quita el hecho de que como son es el fruto de nuestro comercio cognoscitivo con ellas. $Y$ cada relación cognoscitiva con la realidad da lugar en esencia a un ideal o real mapa: de palabras, de esquemas, de figuras ,de imágenes, de cálculos."

A su vez, Zalamea asocia a la pluralidad de la imaginación pragmática de las hojas-mundo las superficies (matemáticas) de Riemann.

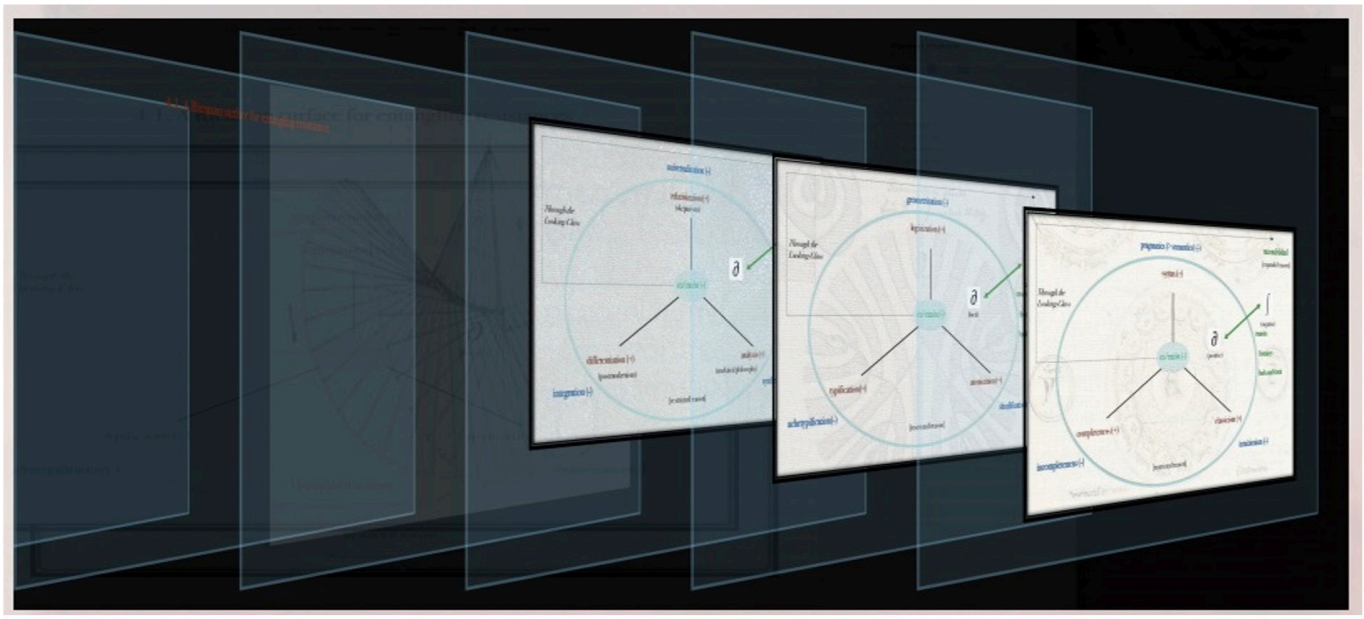

Fernando Zalamea, 2017, Pluralidad (multidimensional) de la imaginación pragmática y superficies de Riemann 


\section{Tercio Creciente}

Revista de Estudios en Sociedad, Artes y

Gestión Cultural

ISSN: 2340-9096

DOI: https://dx.doi.org/10.17561/rtc.20.6424

Investigación

Maneras de habitar los espacios desde la mirada estética

Julio 2021

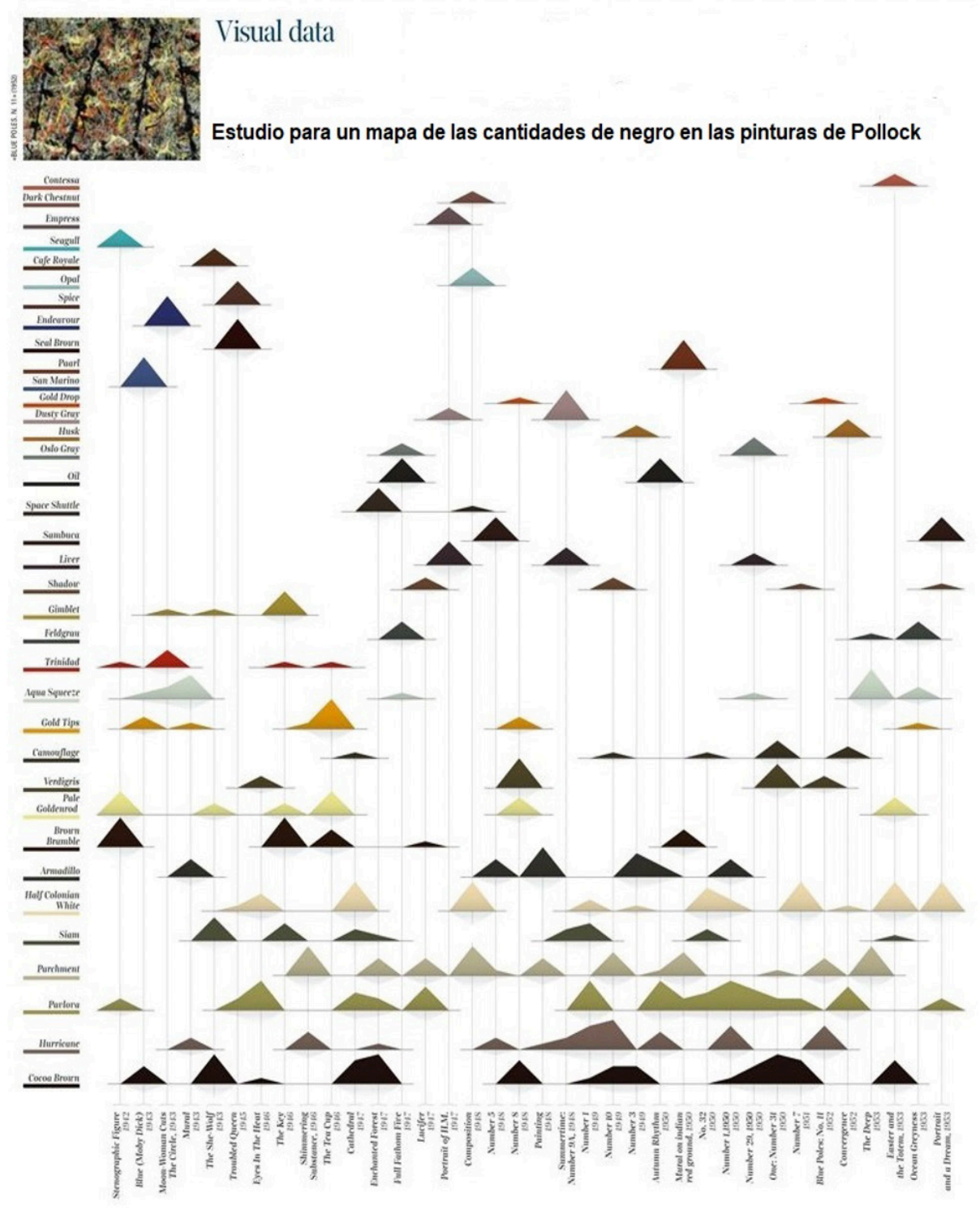

Density Design Lab (Politecnico di Milano), (2014). Estudio para un mapa de las cantidades de negro en las pinturas de Pollock.

Las conexiones pueden ser más o menos significativas, más o menos interesantes, más o menos fantásticas. La teoría de los gráficos es una teoría sin axiomas. Como en un laberinto lleno de trampas y desvíos, se pueden tomar caminos equivocados y uno puede perderse pero el movimiento desencadenado para encontrar una salida es vital. 


\section{Tercio Creciente}

DOI: https://dx.doi.org/10.17561/rtc.20.6424 Investigación
Maneras de habitar los espacios desde la mirada estética

Julio 2021

John Pickles, profesor de Geografía en la Universidad de Carolina del Norte, en su ensayo A History of Spaces [Una historia de los espacio] (2004), subraya que la multiplicación de estas prácticas ha sorprendido e impresionado a los cartográficos y a los geógrafos, sorprendidos por el interés mostrado en su disciplina que nunca había sido tan frecuentada en los últimos años. Pickles se pregunta también si estas prácticas multidisciplinares son capaces de indicar nuevas modalidades de investigación o representativas de la sociedad contemporánea o si no son un mero régimen visual que secunda el deseo de mapear un fin en sí mismo.

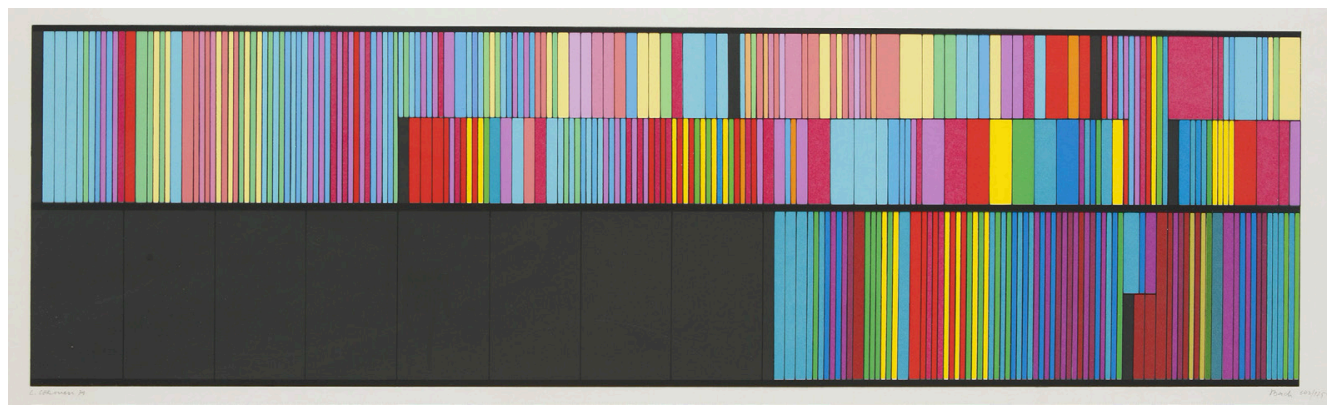

Luigi Veronesi (1978) Contrapunto bachiano [Contrapunto bachiano

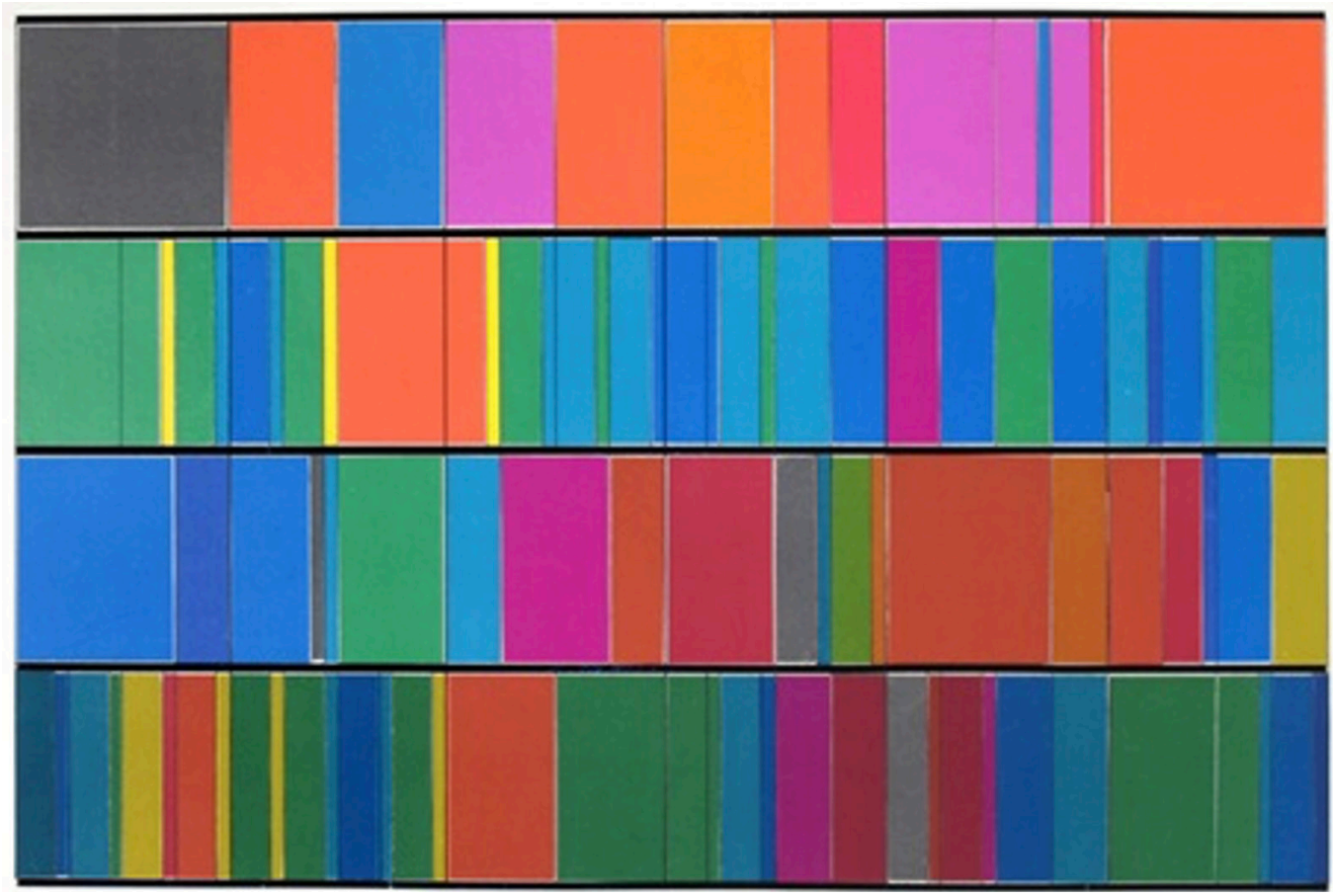

Luigi Veronesi (1975) El arte de la fuga (Bach) 


\section{Tercio Creciente}

DOI: https://dx.doi.org/10.17561/rtc.20.6424

Investigación
Maneras de habitar los espacios desde la mirada estética Julio 2021

Esto, sin embargo, es un aspecto que se puede criticar sólo a posteriori, después de haber emprendido una investigación y verificado que, quizás, los resultados no conducen a nada. Y, en cualquier caso, el ejercicio mental de representación, a través del uso de gráficos y mapas me parece significativo y útil en sí mismo.

El estudio realizado por el 'Lab design' del Politécnico de Milán es un mapa sobre la cantidad de negro presente en las pinturas de Pollock. Pero también las tablas cromáticas del artista Luigi Veronesi (Bolpagni, Di Brino y Savettieri, 2011) sobre los contrapuntos musicales y las fugas bachianas, los polariscopios de Bruno Munari y sus percepciones tecnológicas (Cerritelli, 2017), son obras de arte y son también mapas que usan herramientas y referencias no convencionales y que nos orientan en un mundo de relaciones complejas.

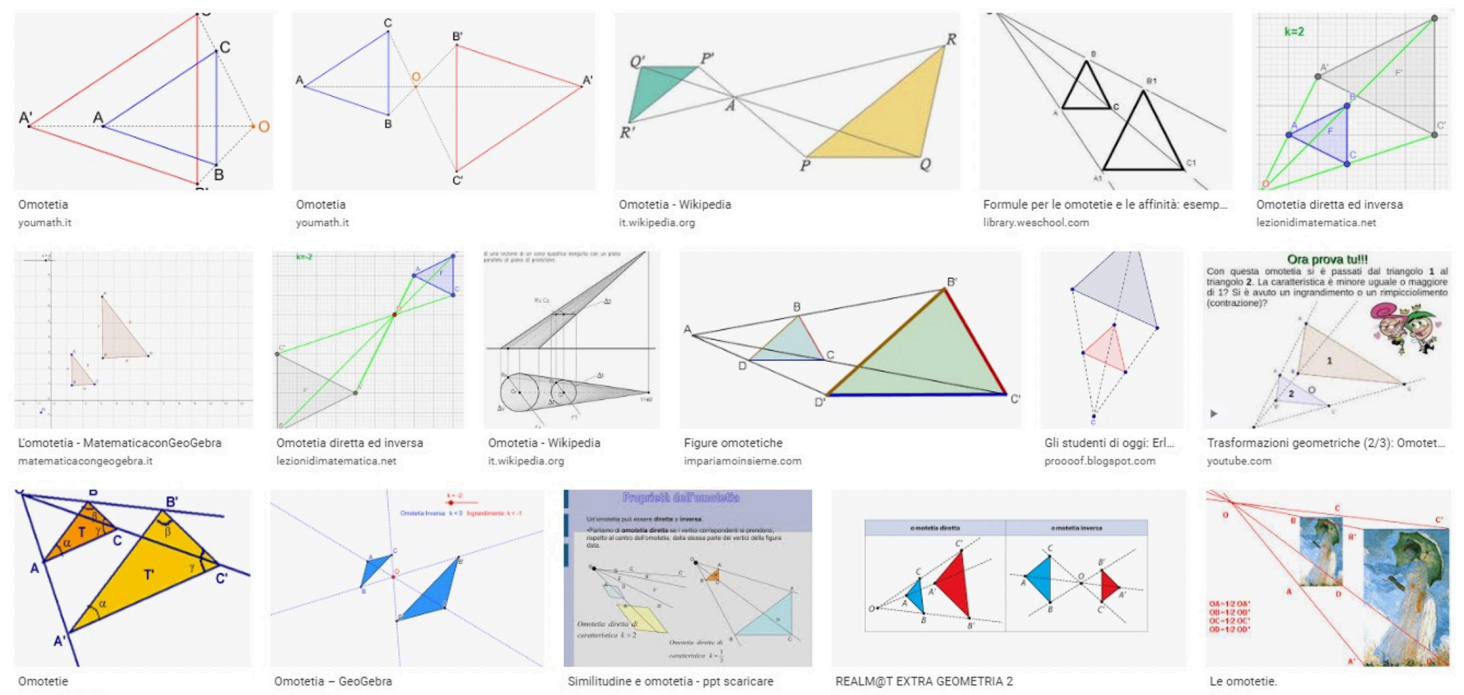

Por la autora, foto de pantalla de internet (2020) Ejemplos de homotetias geométricas

Todos estos ejemplos ponen de relieve el valor de la interdisciplinariedad, en una forma de recomposición del saber que favorece el desarrollo de intuiciones sobre las relaciones que, generalmente, escapan a la observación. Analogías, estructuras, comportamientos, isomorfismos y homotetias (en términos matemáticos), que ayudan a la creatividad y favorecen también un cambio cualitativo en las dinámicas de enseñanza/aprendizaje (Anceschi, p. 148). 


\section{Tercio Creciente}

DOI: https://dx.doi.org/10.17561/rtc.20.6424

Investigación
Revista de Estudios en Sociedad, Artes y

Gestión Cultural

ISSN: 2340-9096
Número 20

Maneras de habitar los espacios desde la mirada estética

Julio 2021

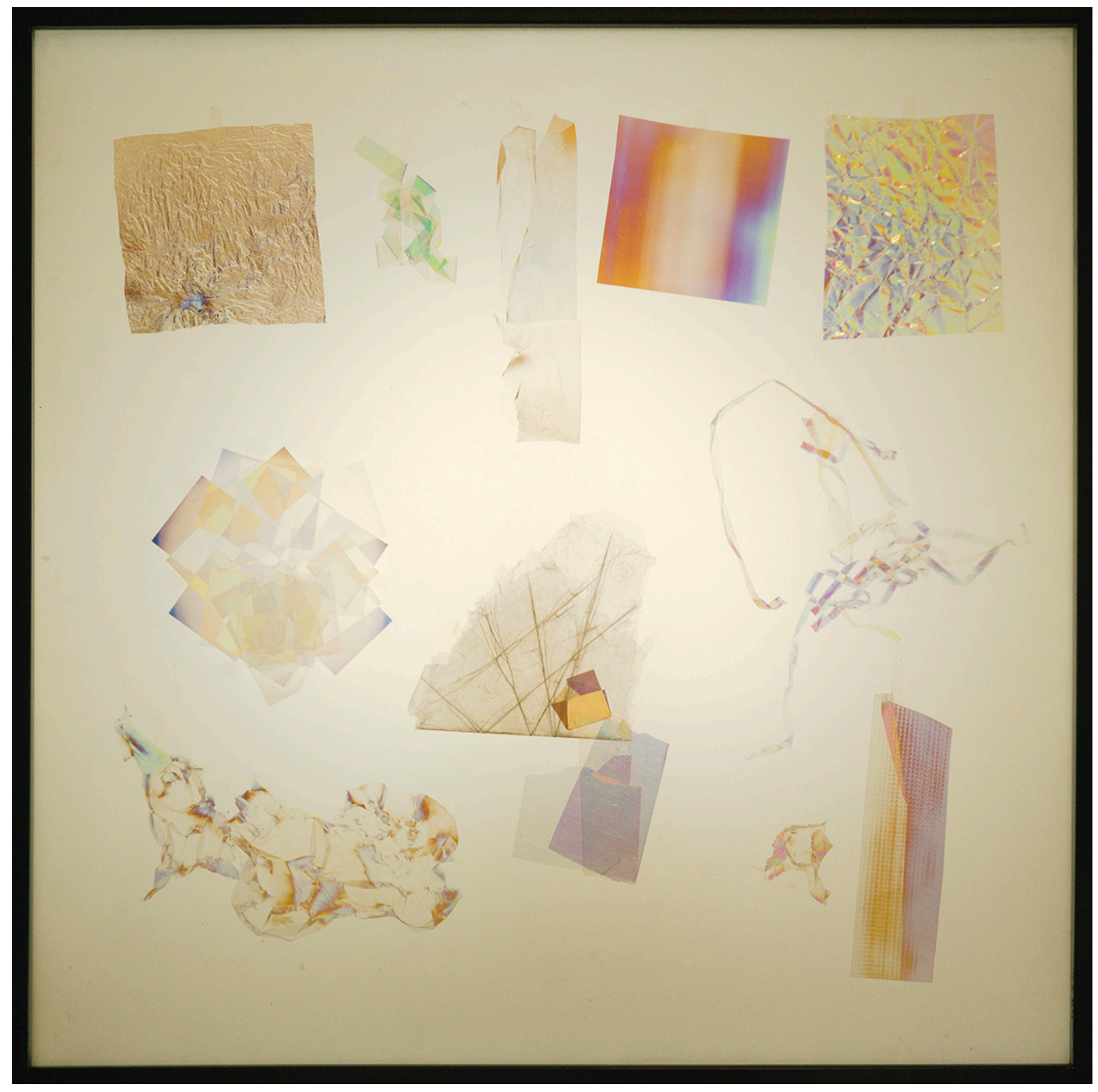

Bruno Munari (1967) Polariscopio 


\section{Tercio Creciente}

DOI: https://dx.doi.org/10.17561/rtc.20.6424

Investigación
Maneras de habitar los espacios desde la mirada estética Julio 2021

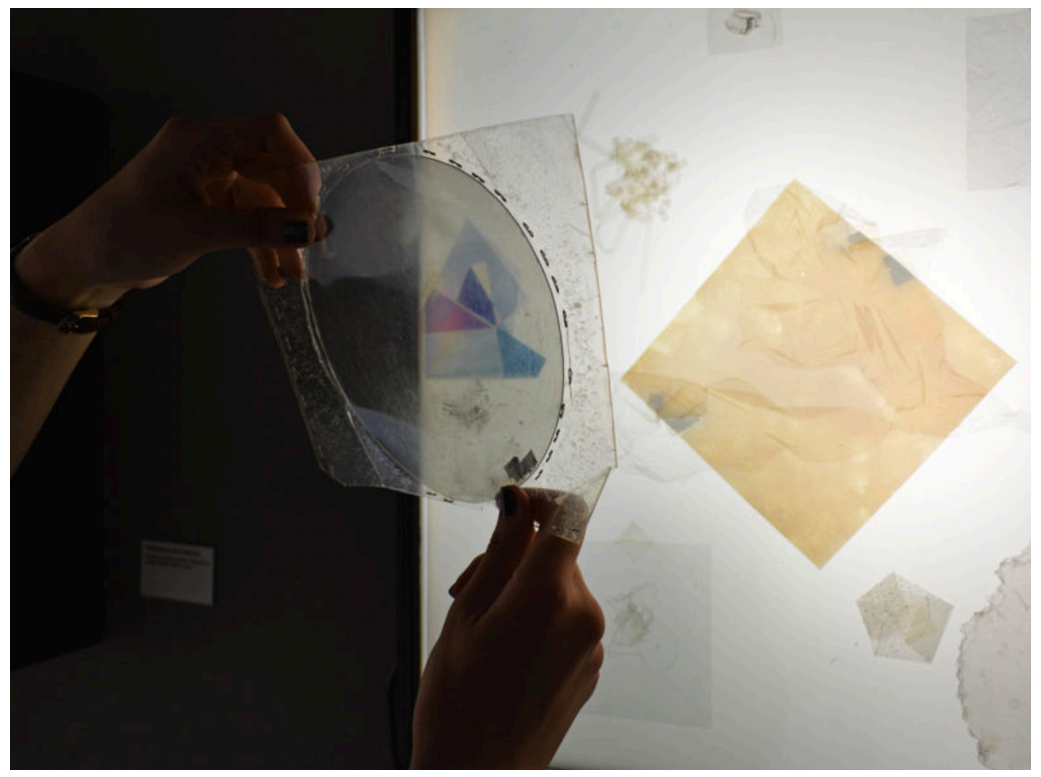

Bruno Munari, (1967) Percepción tecnológica. Polariscopio.

Italo Calvino, en sus Lecciones americanas (1993)propone algunas categorías: ligereza, rapidez, exactitud, visibilidad, multiplicidad; a éstas, a continuación, añadirá también las categorías de 'comenzar y terminar' y la de la 'consistencia'.

Calvino aborda este tema principalmente en relación con el arte y la literatura. Por ejemplo, citando al poeta Leopardi, observa, desde el punto de vista de la categoría de 'exactitud', la manera en que Leopardi pone una atención extremadamente precisa y meticulosa en la composición de cada imagen, en la definición minuciosa de los detalles, en la elección de los objetos, de la iluminación, de la atmósfera, para alcanzar la vaguedad deseada.

Según Calvino exactitud significa, sobre todo, tres cosas: un dibujo de la obra bien definido y calculado; la evocación de imágenes visuales nítidas, incisivas, memorables, icónicas; y un lenguaje lo más preciso posible como vocabulario y como rendición de los matices del pensamiento y de la imaginación.

Gabriele Lolli, en su Discurso sobre las matemáticas (2011), retomando la categoría de la 'exactitud' calviniana, sostiene que no hay nada que cambiar para aplicar estas tres indicaciones a las matemáticas porque la precisión y la exactitud son las cualidades que más caracterizan a las matemáticas. 
Lolli señala que, si se somete a una observación rigurosa la exactitud de los procesos de demostración, se puede llegar a una paradoja combinación de exactitud e incertidumbre. Es decir, el matemático produce la incertidumbre trabajando con la máxima exactitud.

Y cita a Paul Valèry (autor querido también a Calvino) cuando afirma que "el determinismo es la única manera de representarnos el mundo y la incertidumbre es la única manera de vivir allí". (Lolli, 2011, p.143)

Dice Lolli (2011, p.156): "el matemático, como el poeta, está siempre orientado al futuro. (...) E incluso en la escuela se deben discutir los problemas abiertos, llegar a tener estudiantes que tienen (o encuentran) problemas que no saben si van a resolver, pero que se han colocado por sí mismos".

El lenguaje y el uso de las palabras ha ido adquiriendo en el tiempo una gran importancia tanto en el arte (a partir de Duchamp y continuando con el arte conceptual) como en las matemáticas y en la ciencia en general, hasta la coincidencia entre el lenguaje y el metalinguaje. Por ejemplo, ¿sería interesante comparar las pizarras de Beuys con las pizarras de Zalamea o no?

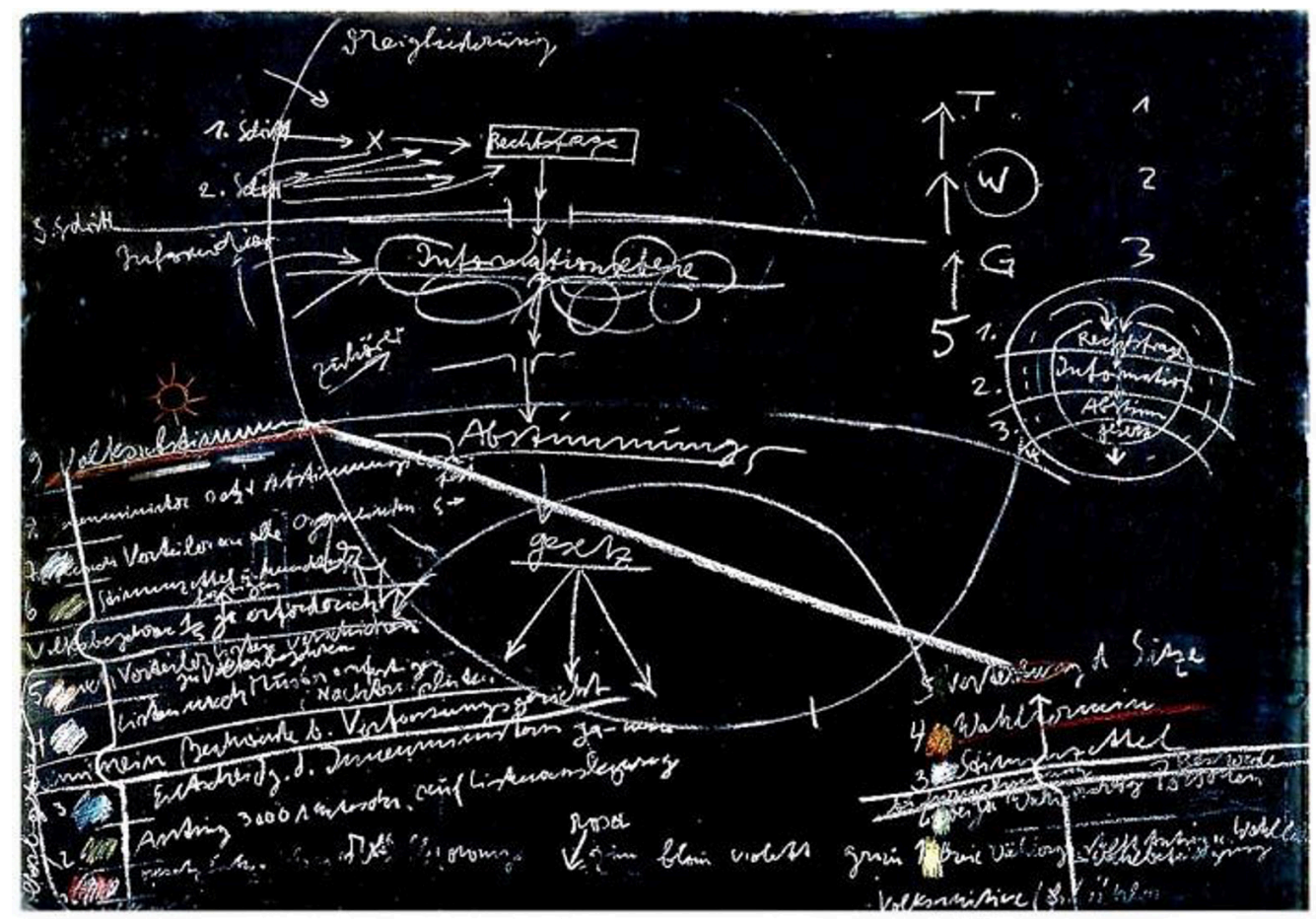

Joseph Beuys (1971) Blackboard from the office for direct democracy [Pizarra de la oficina para la democracia directa], $1216 \times 914 \times 18 \mathrm{~mm}$ 


\section{Tercio Creciente}

DOI: https://dx.doi.org/10.17561/rtc.20.6424 Investigación

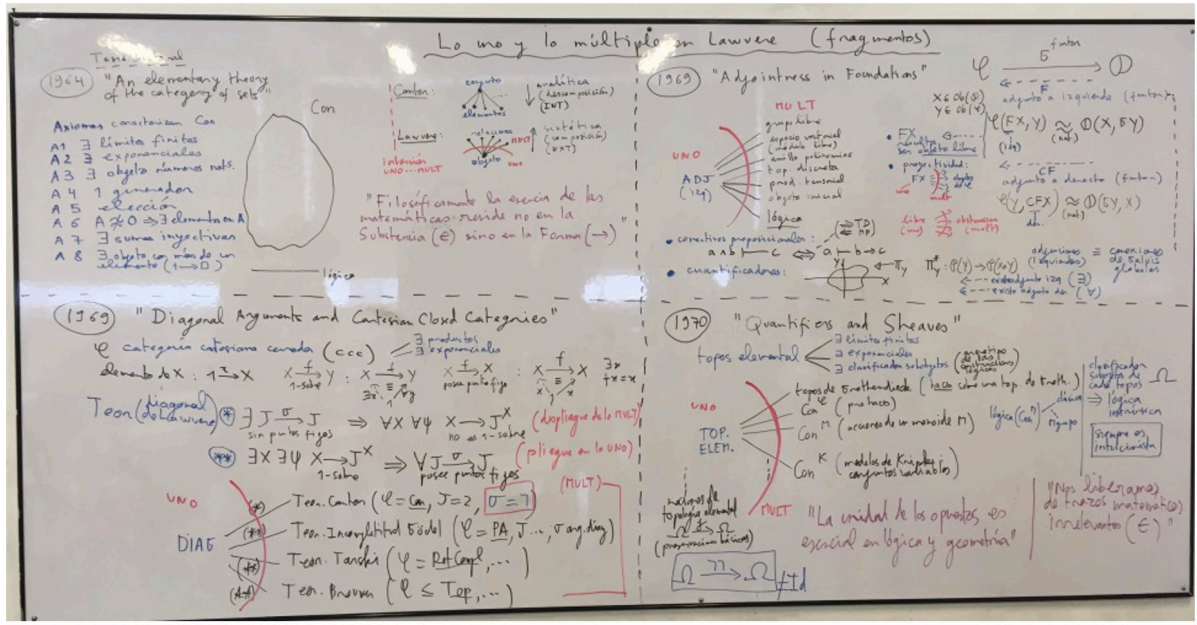

Fernando Zalamea (2019) Lo uno y lo multiplo. Pizarra.

En la comparación nos ayuda la categoría de 'ligereza'. Calvino busca en la ciencia la nutrición el concepto de sustracción de peso o como lo define el mismo Calvino: “...un aligeramiento del lenguaje por el cual los significados son transportados sobre un tejido verbal como sin peso, hasta asumir la misma rareza consistencia." (2016, p. 19).
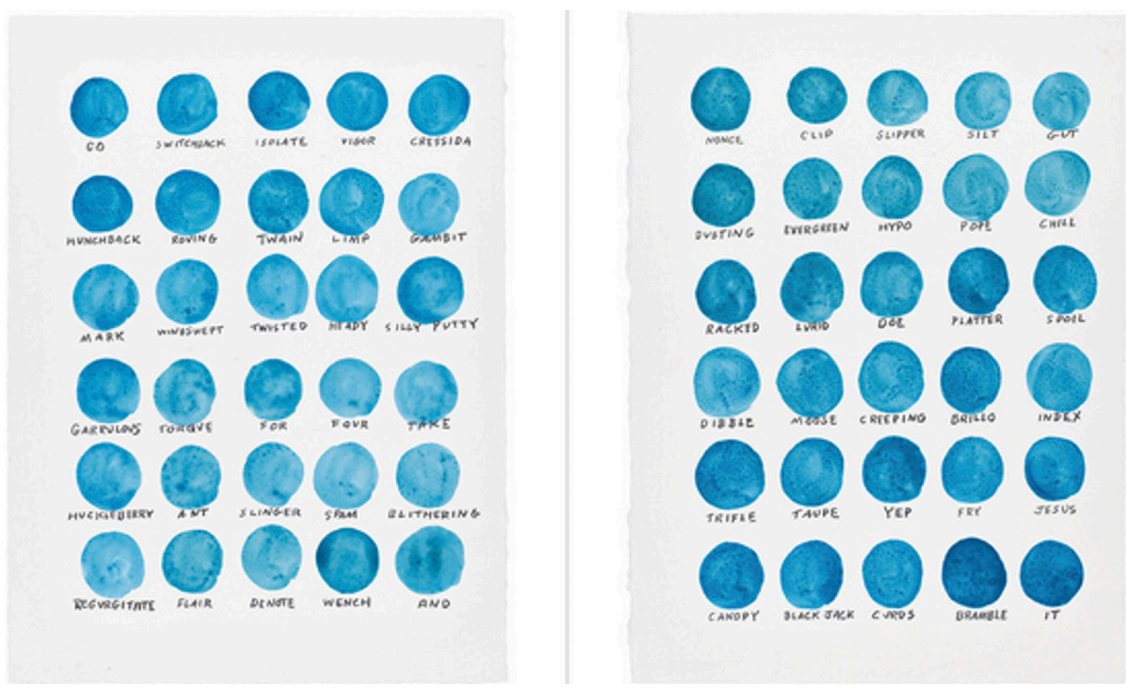

Roni Horn (2013) Remembered Words [palabras recordadas]. 


\section{Tercio Creciente}

DOI: https://dx.doi.org/10.17561/rtc.20.6424

Investigación
Maneras de habitar los espacios desde la mirada estética

Julio 2021

En la obra Remembered words [Palabras recordadas], del artista Roni Horn, es evidente la búsqueda de una relación entre la palabra, el color, la emoción, la lógica.

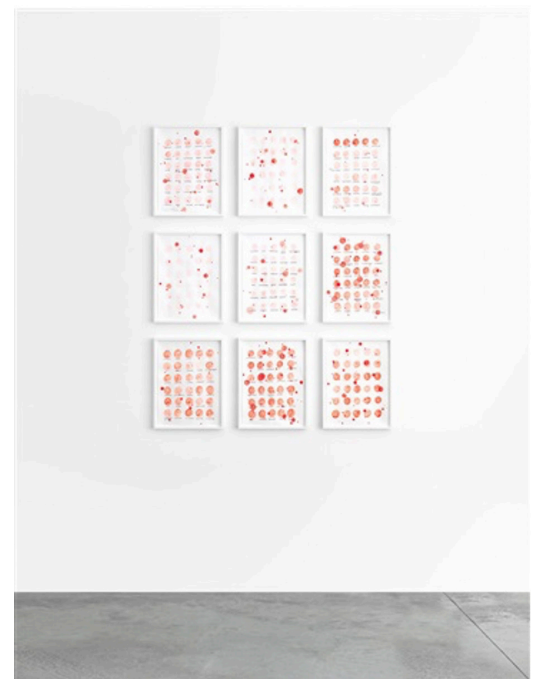

Roni Horn (2013) Remembered Words [palabras recordadas

Para Roni Horn, el dibujo es una parte vital de su práctica a la que siempre vuelve. El dibujo le permite examinar los temas del lenguaje y de la identidad junto con la poética de la yuxtaposición y de la materialidad. Se advierte el interés por el juego de palabras y las correspondencias resbaladizas entre significado y memoria que crean un vocabulario cultural infinitamente complejo y abierto. Cada una de las obras individuales consta de nueve partes dispuestas en una cuadrícula $3 \times 3$ de dibujos enmarcados. Cada diseño mide e $38^{\prime} 1$ ×27'94 centímetros y contiene círculos pintados a mano con acuarela. Estos círculos se presentan en un esquema de cuadrícula con palabras escritas debajo de ellos o aparecen en grupos desordenados con palabras que saltan dentro y fuera de manera más retórica. Semejante a algo como una taxonomía científica, estas constelaciones ordenadas de círculos y notaciones corresponden vagamente a su título y, al unirse unas a otras, construyen correlaciones que son al mismo tiempo lógicas pero también desorientadoras. Roni Horn ha estado llevando a cabo durante años también un trabajo de colección de cuentos-retrato relacionados con el tiempo meteorológico en Islandia y sus variaciones. En esta época de cambio climático del planeta 
la colección de cuentos de Roni Horn (1997) se ofrece como una herramienta adicional de investigación para complementar los estudios sobre los problemas humanos relacionados con el calentamiento global.

Por otro lado, volviendo a la categoría de la ligereza, Sergio Lombardo, en su investigación sobre la diversión descubre e inventa algoritmos estocásticos que luego han sido utilizados también en el ámbito científico. Por ejemplo, en la búsqueda de algoritmos generadores de caras. En este caso, Lombardo se ha planteado las siguientes tres preguntas: ¿Cuál es el algoritmo estocástico que genera el mayor número de caras imprevisibles y masivamente diferentes entre el agujero? ¿Cuál es el mapa mínimo que, si se deforma con el método RAN, conduce más a menudo a formas aleatorias en las que se reconocen caras imprevisibles? ¿Cuál es el procedimiento automático RAN que, cuando se aplica en el mapa, conduce más a menudo a formas aleatorias en las que se reconocen caras impredecibles?

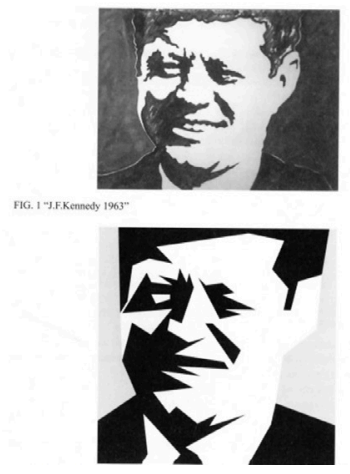

Sergio Lombardo (1995) Algoritmos estocásticos que generan caras impredecibles

La búsqueda de algoritmos estocásticos de Lombardo, por un lado ironía sobre la rigidez de los procesos matemáticos y pone de relieve la 'gracia' de los resultados obtenidos $y$, por otro, contribuye seguramente a la investigación matemática, aunque en una forma 'aligerada' con la fantasía. 


\section{Tercio Creciente}

DOI: https://dx.doi.org/10.17561/rtc.20.6424

Investigación
Maneras de habitar los espacios desde la mirada estética

Julio 2021

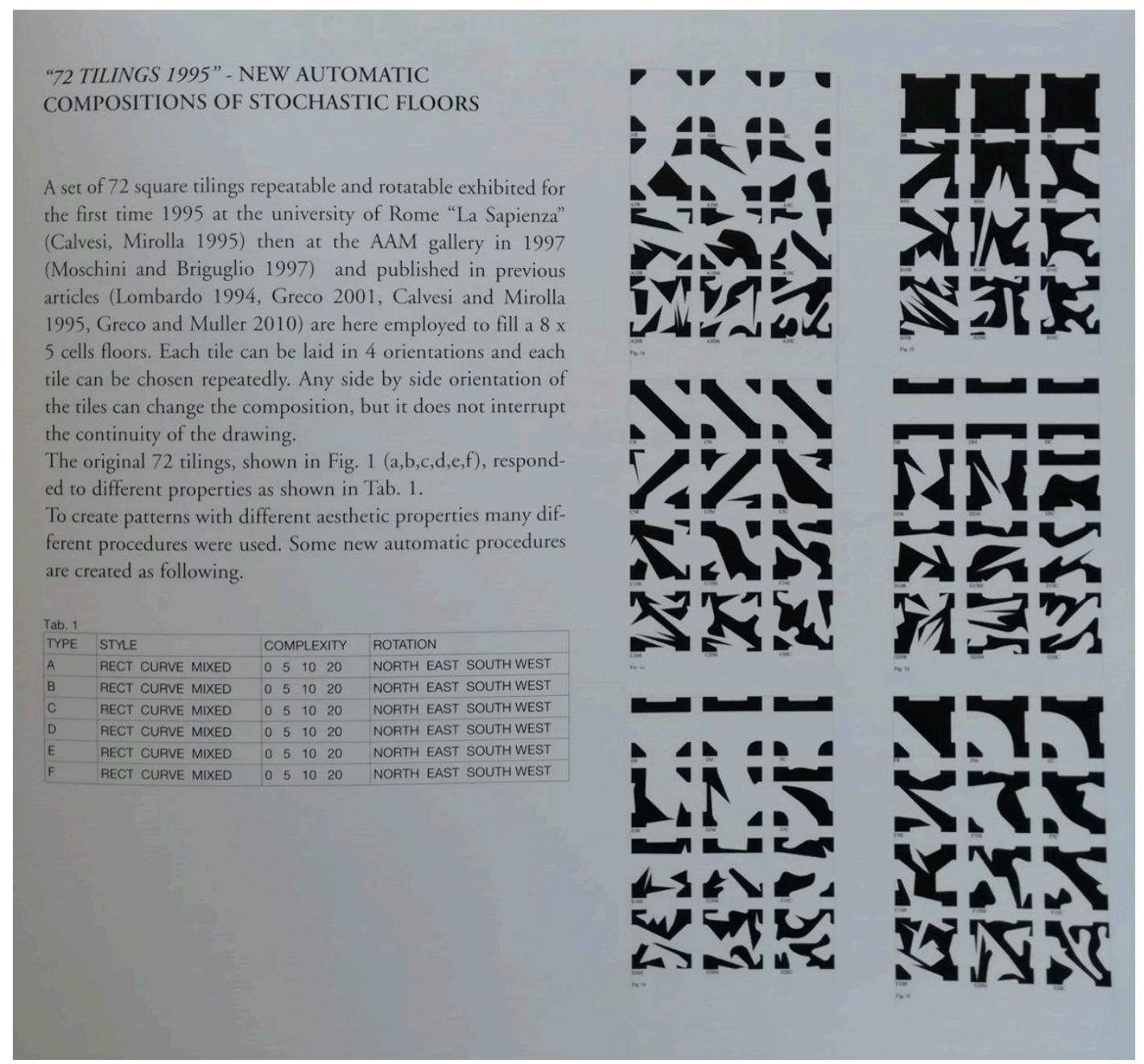

Sergio Lombardo (1995) 72 Tilings [72 teselados]

En la obra de Sol Lewitt, la contribución epistemológica a la ciencia matemática es notable y su trabajo tiene repercusiones importantes también en los ámbitos de la formación tanto en el campo científico como en el campo de la educación en la relación con el espacio. Sus Wall drawings [Dibujos murales] recogen la experiencia de una gran colaboración entre el arte, las matemáticas y la arquitectura 


\section{Tercio Creciente}

Revista de Estudios en Sociedad, Artes y

Gestión Cultural

ISSN: 2340-9096

Maneras de habitar los espacios desde la mirada estética

Julio 2021

DOI: https://dx.doi.org/10.17561/rtc.20.6424

Investigación

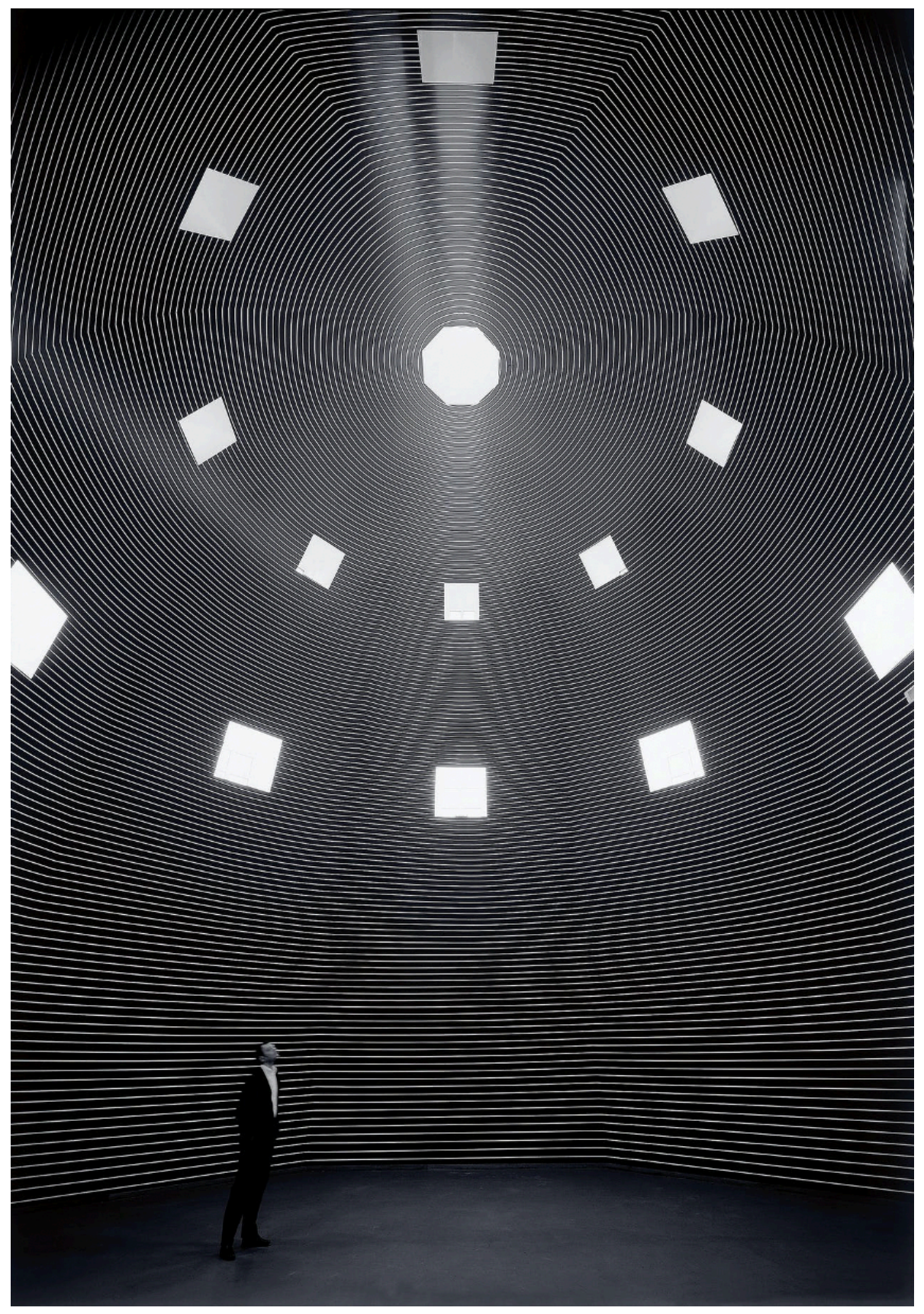

Sol LeWitt (2000) Bonfanten Museum 


\section{Tercio Creciente}

DOI: https://dx.doi.org/10.17561/rtc.20.6424

Investigación

Maneras de habitar los espacios desde la mirada estética

Julio 2021

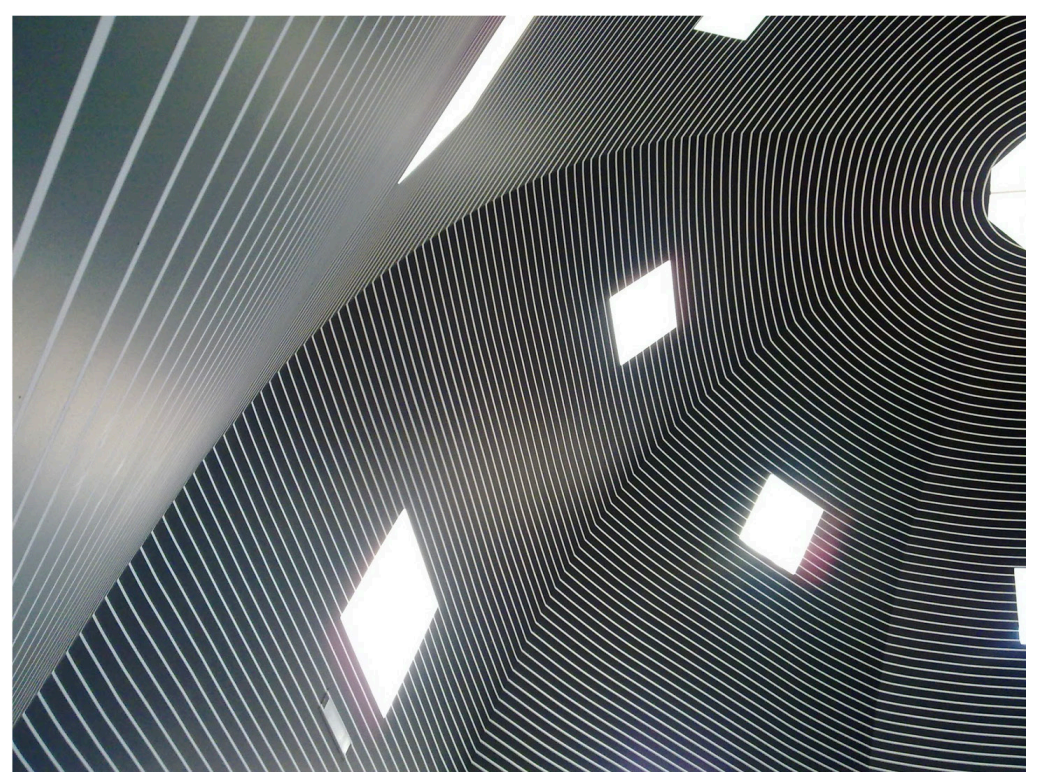

Sol LeWitt (2000) Bonfanten Museum

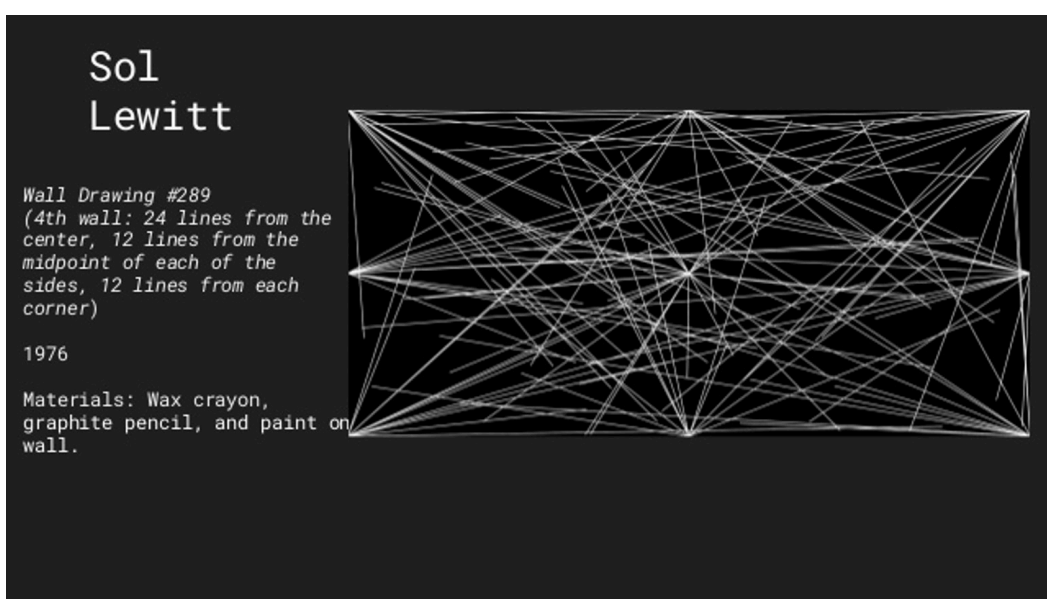

SSol LeWitt (1976) Wall Drawing \#289 [Dibujo mural número 289] 


\section{Tercio Creciente}

DOI: https://dx.doi.org/10.17561/rtc.20.6424

Investigación
Maneras de habitar los espacios desde la mirada estética

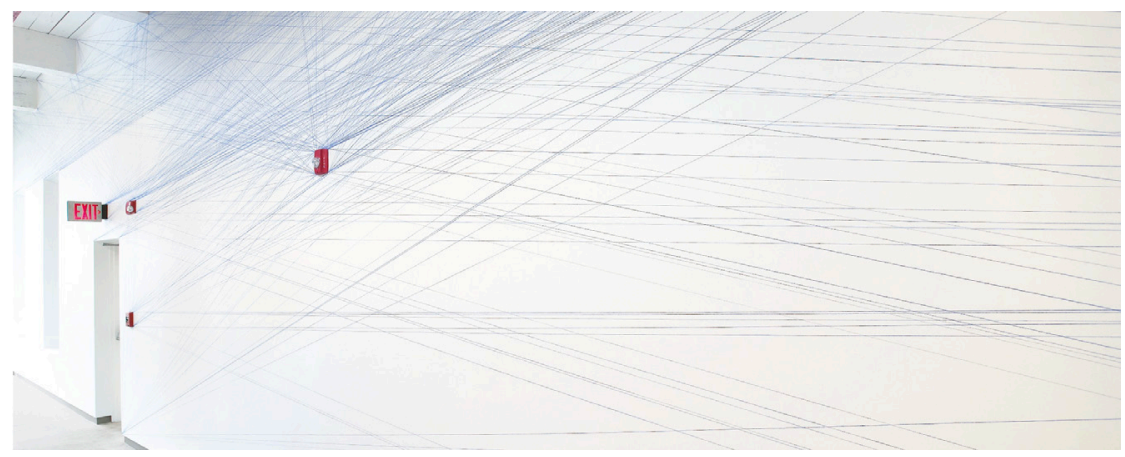

Sol LeWitt (1970) Wall Drawing \#51. All architectural points connected [ Dibujo mural número 51. Todos los puntos arquitectónicos conectados]

El trabajo de la artista Silvia Hell se inserta en este contexto de investigación. Por ejemplo, con la obra A Form of History [Una forma de historia] (2011) se investigan las unidades de medida y las referencias de los límites geopolíticos conocidos por las fuentes institucionales. http://silviahell.eu/works/a-form-of-history).

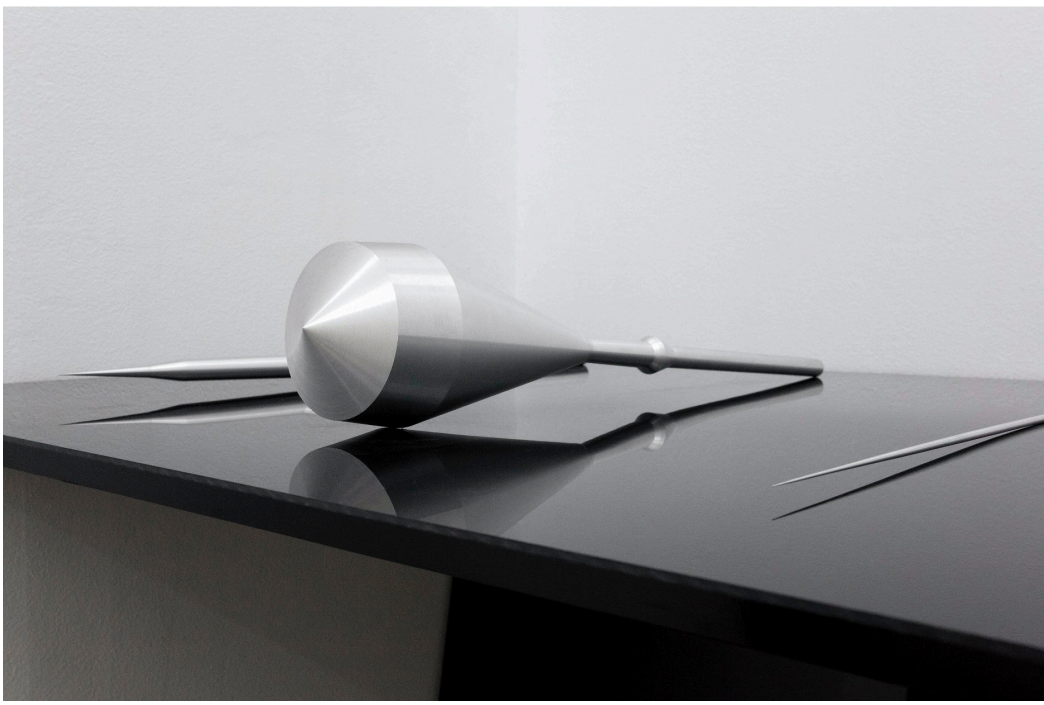

Silvia Hell (2011-2012) A Form of History [Una forma de historia]. Animation HD, silent, 09' 32" 


\section{Tercio Creciente}

DOI: https://dx.doi.org/10.17561/rtc.20.6424 Investigación
Maneras de habitar los espacios desde la mirada estética

Julio 2021

Y los conceptos de medida, regla, modelo se convierten en categorías esenciales para definir la obra.

Esto demuestra la existencia de un contexto creativo que genera una relación espontánea entre el arte y las matemáticas.

Tomás Saraceno está realizando numerosas obras en colaboración con varios científicos, con la idea de que todos puedan contribuir colectivamente a un ejercicio de armonización planetaria. A partir de su trabajo con las arañas que tejen redes-telarañas realiza enormes gráficos que representan una abstracción de los ecosistemas y de las redes de información que conectan todo lo que es vivo y no vivo. Por ejemplo, realiza las Cartas de Aracnomancia, con la idea de utilizar el ritmo de las vibraciones de las telarañas y de la 'sonificación' de las ondas gravitacionales procedentes del universo, para poder percibir fenómenos que van más allá de la percepción humana.

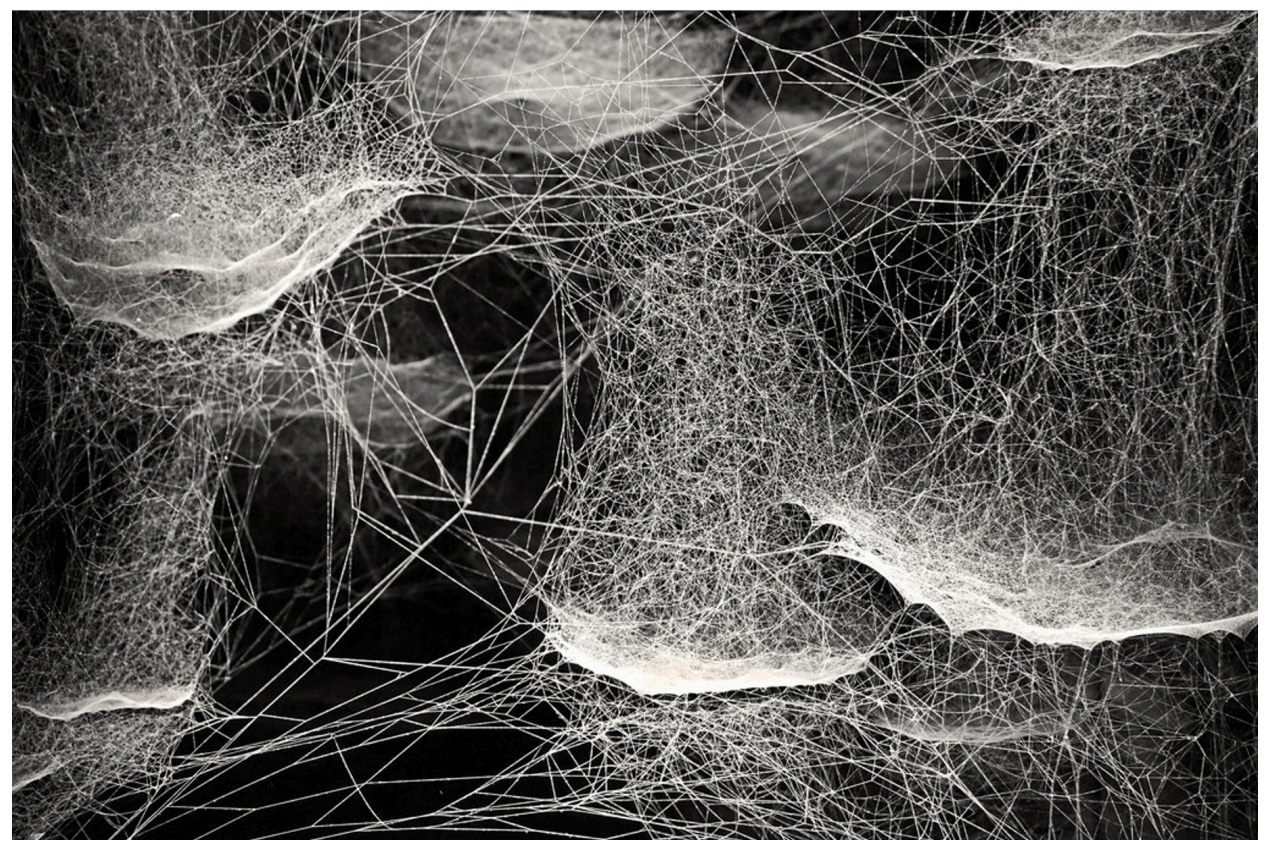

Tomas Saraceno (2018) More than humans [màs que humanos]. 
Otra obra de Tomas Saraceno, Connettoma, toma el nombre del mapa de las conexiones neuronales del cerebro, compuesto por un conjunto de esculturas poliédricas suspendidas, modeladas sobre la forma de las burbujas de jabón. Los temas relativos al 'antropoceno' y al 'aeroceno' (término acuñado por el mismo Tomas Saraceno) son enfocados por muchos artistas contemporáneos, aunque, a veces, esto puede provocar el efecto secundario de la anestesia estética (Bindi, 2019). Según el antropólogo Tim Ingold, el mundo se ha vuelto problemático precisamente porque es objeto de contemplación alejado del dominio de la experiencia vivida. Es decir, en todos los aspectos de la vida cotidiana somos superados por procesos de transformación en curso en un contexto que antes conocíamos mientras que ahora se nos escapa. Este proceso es, sobre todo, un acontecimiento estético: los sistemas sensoriales y perceptuales han sido condicionados de manera tan repentina que tienen poca conciencia, dado que el ambiente que nos rodea cambia rápidamente y de forma solapada. Panoramas de paisajes 'antropocenos' por ejemplo marcados por la deforestación o por la urbanización explosiva, hoy parecen totalmente naturales.(Bindi, 2019, p. 127)

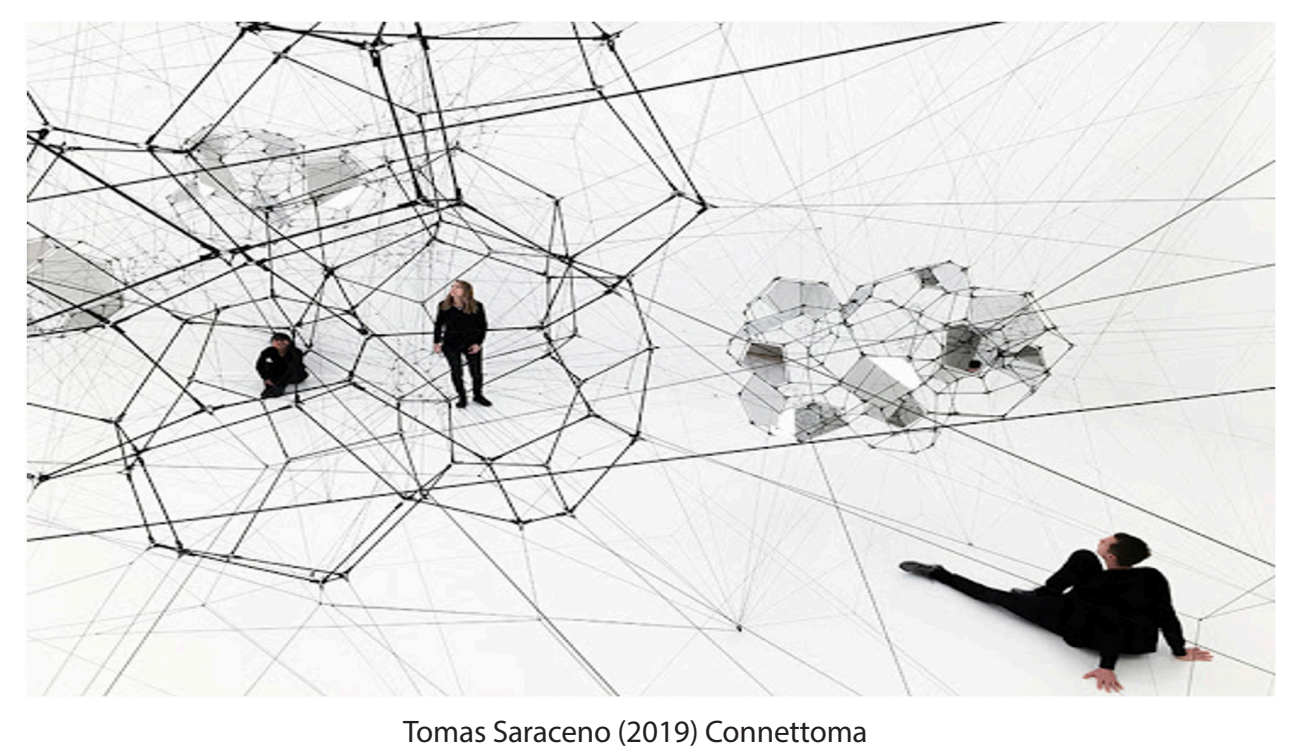

Las fotografías de Armin Linke reflejan un poco este fenómeno de la anestesia estética. Mientras que en los jardines de Michele Guido es fundamental la atención a los fenómenos vinculados al desarrollo de las plantas y a sus geometrías, con las que el artista define conexiones complejas y matemáticas. La modularidad del espacio, los píxeles y la sección áurea son temas recurrentes en sus obras. 


\section{Tercio Creciente}

Revista de Estudios en Sociedad, Artes y

Gestión Cultural

ISSN: 2340-9096

DOI: https://dx.doi.org/10.17561/rtc.20.6424

Maneras de habitar los espacios desde la mirada estética Julio 2021

Investigación

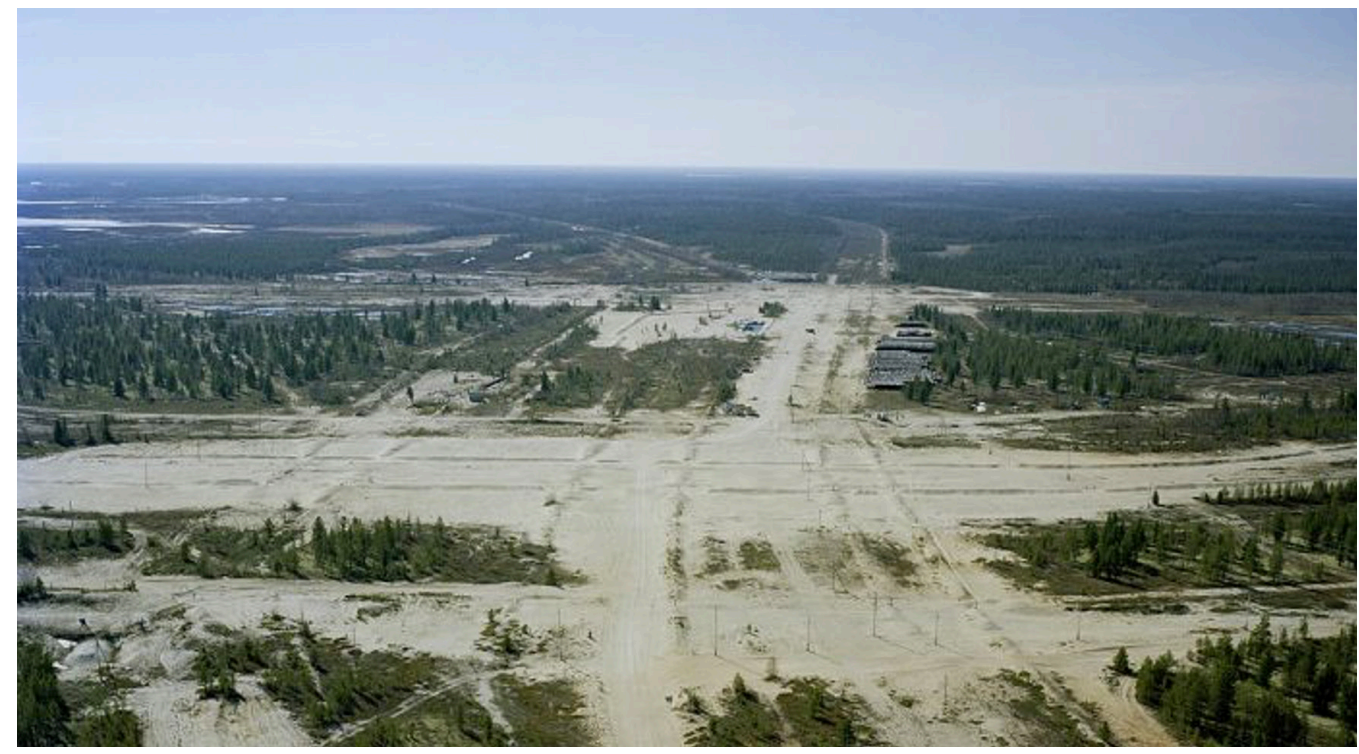

Armin Linke (2011) Empalme del gasoducto, Nadym, Rusia

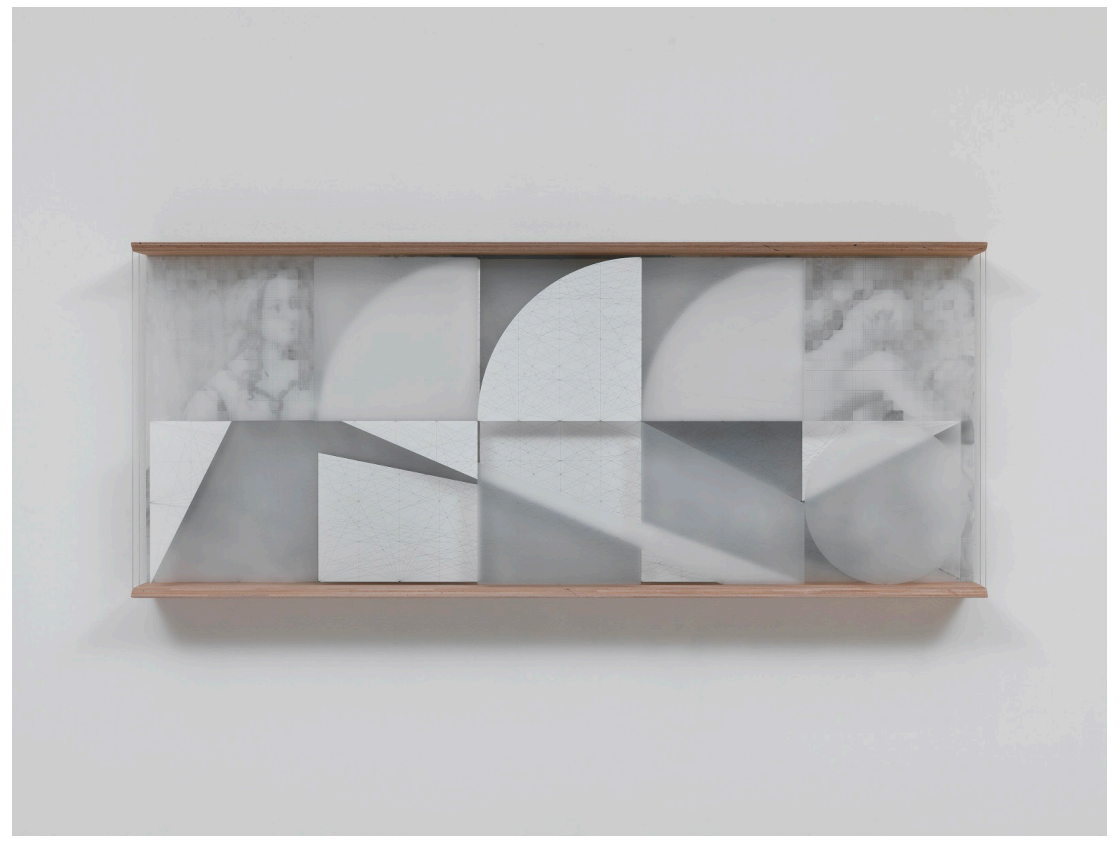

Michele Guido (2017) Estudio para el jardín de Venus y Marte 


\section{Tercio Creciente}

DOI: https://dx.doi.org/10.17561/rtc.20.6424

Investigación
Maneras de habitar los espacios desde la mirada estética

\section{Conclusiones}

En este artículo, a la luz de lo que se desprende del análisis de Bruno Latour en el libro Investigación sobre los modos de existencia, he investigado algunas relaciones entre las categorías literarias calvinianas de la ligereza, de la velocidad, de la exactitud, la visibilidad, la multiplicidad y la consistencia, transfiriéndolas a diferentes contextos artísticos y científicos y poniendo de relieve los flujos de intercambio en las fronteras entre los diferentes territorios del conocimiento artístico y matemático, en particular.

Comparadas, las obras de algunos artistas contemporáneos (Joseph Beuys, Michele Guido, Silvia Hell, Roni Horn, Armin Linke, Mark Lombardi, Sergio Lombardo, Sol Lewitt, Bruno Munari, Jackson Pollock, Tomas Saraceno, Luigi Veronesi) y las obras de los matemáticos contemporáneos Alexander Groetendieck y Fernando Zalamea, revelan la reciprocidad epistemológica en función de la ampliación de la percepción humana.

Utilizando los métodos de la filosofía pragmática, a través del uso de la hoja-mundo y de los gráficos existenciales de Charles Peirce, la lógica de las analogías, de las similitudes y de los contrastes dialécticos y la lógica intuicionista, surgen, en las obras estudiadas, las relaciones fenomenológicas entre los elementos expresivos de las obras de los artistas investigados y los significados actuales, vinculados a los diferentes ámbitos disciplinarios.

Por último, con las herramientas ofrecidas por la A/R/Tografía, se traza un mapa de relaciones entre los elementos icónicos, las categorías calvinianas y los conceptos matemáticos de homotetia, isomorfismo, lista, red, superficie, proceso estocástico.

\section{Referencias}

Anceschi, A., (2015) Musica e Arti Visive nell'educazione: qualità dell'apprendimento in una esperienza realizzata secondo un approccio interdisciplinare [Música y artes visuales en la educación: cualidad del aprendizaje en una experiencia realizada con una perspectiva interdiscilinar]. Sevilla/Trento, https://dialnet.unirioja.es/, http://eprints-phd.biblio.unitn.it/.

Baldacci, C. (2016). Archivi impossibili [Archivos imposibles]. Johan \& Levi. 


\section{Tercio Creciente}

DOI: https://dx.doi.org/10.17561/rtc.20.6424 Investigación

Bindi, G. (2019). Arte, Ambiente, Ecologia, Postmedia Books.

Blossfeldt, K. (1930) L'incanto della flora [El encanto de la flora]. Taschen.

Bolpagni, P., Di Brino, A., y Savettieri, C. (a cura di) (2011). Ritmi visivi. Luigi Veronesi nell'astrattismo europeo [Ritmos visuales. Luigi Veronesi en la abstracción europea]. Ragghianti.

Calvino, I. (1993) Lezioni americane [Lecciones americanas | Seis propuestas para el próximo milenio]. Mondadori.

Dewey, J., 1934, Arte come esperienza [El arte como experiencia]. Aesthetica.

Eco, U. (2009). Vertigine della lista [El vértigo de las listas]. Bompiani.

Horn, R. (1997). You are the Weather [Usted es el clima]. Scalo.

Irwin, R., Barney, D. T. y Golparian, S. (2017). A/R/Tografia como Metodología para la Investigación Visual. En R. Marín Viadel y J. Roldán (Eds.) Ideas Visuales. Investigación Basada en Artes e Investigación Artística, (pp 134-167). Universidad de Granada.

Jameson, F. (1995). The geopolitical Aesthetic: Cinema and Space in the World System. [Estética geopolítica: Cine y espacio en el sistema mundial].Indiana University Press.

Jódar Miñarro, A, (ed.). (2006) Por dibujado y por escrito. Universidad de Granada.

Klee, P. (2009). Teoria della forma e della figurazione [Teoría de la forma y de la figuración]. Feltrinelli.

Latour, B. (2009). Non siamo mai stati moderni [Nunca hemos sido modernos]. Eleuthera. -( 2012). Un enquête sur les modes d'existence [Una encuesta sobre los modos de existencia]. La Decouvert.

Latour, B. (2008). Reensamblar lo social. Una introducción a la teoría del actor-red. Manantial.

Lolli, G. (2011). Discorso sulla matematica [Discurso sobre la matemática]. Bollati Boringhieri. 


\section{Tercio Creciente}

DOI: https://dx.doi.org/10.17561/rtc.20.6424

Investigación
Maneras de habitar los espacios desde la mirada estética Julio 2021

- (2016). Le Lezioni perdute di Calvino [Las lecciones perdidas de Calvino]. Utet. Lombardo, S. (2013). Algoritmi stocastici che generano facce imprevedibili [Algorismos estocásticos que generan caras imprevisibles]. Rivista di psicologia dell'arte, 24, pag. 47-52

Merleau-Ponty, M. (2003). Fenomenologia della percezione [Fenomenología de la percepción]. Studi Bompiani.

Peirce, C. S. (2009). Esperienza e percezione: percorsi nella Fenomenologia [Experiencia y percepción: trayectorias en la Fenomenología]. Edizioni ETS.

Peirce, C. S. y James, W. (2000). Che cos'è il pragmatismo [Qué cosa es el pragmatismo]. Jaca Book.

Pickles, J. (2004). A History of Spaces [Una historia de los espacios]. Routledge.

Pignatti, L. (2011). Mind the map [Cuiado con el mapa]. Postmedia Books.

Rickey, G. (1995). Constructivism [Constructivismo]. George Braziller.

Sini, C.(2007). Teoria e pratica del foglio-mondo [Teorría y práctica del 'folio-mundo']. Laterza.

Troiano, C. G. (a cura di). (2014). Le mappe del sapere [Los mapas del saber]. Rizzoli.

Varela, F.,J., Thompson, E., Rosch, E., (1991). La via di mezzo della conoscenza [El camino intermedio del conocimiento]. Feltrinelli.

Warburg., A. (2002). Atlas Mnemosyne. Aragno.

Zalamea, F. (2016). Epistemología e historia de las matemáticas, seminario continuo de filosofíade las matemáticas. Universidad nacional de Colombia,

- (2017). Tecniche della matematica contemporanea per lo sviluppo attuale della filosofia, 2017, seminario presso MECHRì (laboratorio di filosofia e cultura) [Técnicas delas matemáticas contemporáneas para el desarrollo actual de la filosofía, 2017, seminario en MECHRì (laboratorio de filosofía y cultura)]. Milano. -

- (2019). Grothendieck, una guìa a la obra matemática y filosófica. Nomos. 